IZA DP No. 10086

School Feeding and Learning Achievement:

Evidence from India's Midday Meal Program

Tanika Chakraborty

Rajshri Jayaraman

July 2016 


\title{
School Feeding and Learning Achievement: Evidence from India's Midday Meal Program
}

\author{
Tanika Chakraborty \\ IIT Kanpur and IZA \\ Rajshri Jayaraman \\ ESMT Berlin
}

Discussion Paper No. 10086

July 2016

IZA

P.O. Box 7240

53072 Bonn

Germany

Phone: +49-228-3894-0

Fax: +49-228-3894-180

E-mail: iza@iza.org

Any opinions expressed here are those of the author(s) and not those of IZA. Research published in this series may include views on policy, but the institute itself takes no institutional policy positions. The IZA research network is committed to the IZA Guiding Principles of Research Integrity.

The Institute for the Study of Labor (IZA) in Bonn is a local and virtual international research center and a place of communication between science, politics and business. IZA is an independent nonprofit organization supported by Deutsche Post Foundation. The center is associated with the University of Bonn and offers a stimulating research environment through its international network, workshops and conferences, data service, project support, research visits and doctoral program. IZA engages in (i) original and internationally competitive research in all fields of labor economics, (ii) development of policy concepts, and (iii) dissemination of research results and concepts to the interested public.

IZA Discussion Papers often represent preliminary work and are circulated to encourage discussion. Citation of such a paper should account for its provisional character. A revised version may be available directly from the author. 


\title{
ABSTRACT
}

\section{School Feeding and Learning Achievement: Evidence from India's Midday Meal Program*}

\begin{abstract}
We study the effect of the world's largest school feeding program on children's learning outcomes. Staggered implementation across different states of a 2001 Indian Supreme Court Directive mandating the introduction of free school lunches in public primary schools generates plausibly exogenous variation in program exposure across different birth cohorts. We exploit this to estimate the effect of program exposure on math and reading test scores of primary school-aged children. We find that midday meals have a dramatic positive effect on learning achievement: children with up to 5 years of primary school exposure improve their test scores by approximately $10-20 \%$. We further investigate various channels that may account for this improvement including enrollment and nutrition-learning effects, heterogeneous responses by socio-economic status, complementary schooling inputs, and intra-household redistribution.
\end{abstract}

JEL Classification: $\quad 121,125,012$

Keywords: school feeding, learning, midday meal, primary school education

Corresponding author:

Tanika Chakraborty

Indian Institute of Technology

FB 626

Kanpur, UP 208016

India

E-mail: tanikac@gmail.com

\footnotetext{
* We thank ASER for generously sharing their data with us. We are also grateful to seminar and conference participants at DIW and ESPE in Berlin, the Canadian Economics Association's Development Economics Group in Ottawa, ISI Delhi, IGIRD Mumbai, Goethe University Frankfurt, and the University of Sherbrooke for useful comments and suggestions. Nidhi Pande provided excellent research assistance.
} 


\section{INTRODUCTION}

School feeding programs are ubiquitous. The World Food Program estimated that in 2013, 368 million children, or 1 in 5, received a school meal at a total cost of US\$ 75 billion (WFP, 2013). There are two main rationales for this sizable investment. The first is to abate hunger and improve health and nutrition. The second is to improve schooling outcomes.

This paper analyzes the latter by evaluating the impact of India's free school lunch program—which we will refer to by its local moniker, "midday meals"- on learning achievements of primary school children. Proponents argue that free in-school feeding programs have a positive impact on learning through two main channels. First, they encourage enrollment and attendance, both of which afford children the opportunity to learn in the first place. Second, they improve children's nutritional intake: alleviation of short-term hunger facilitates concentration and improved health and nutritional status leads to better cognition and lower absenteeism due to illness.

However, these positive effects are not self-evident. For one, it is not clear whether improved nutrition or enrollment alone suffice. Presumably complementary teaching inputs are also required in order to promote learning in schools. For another, nutritional benefits stand to question if children come from wealthy families and are already well-nourished, or if school meals lead families to substitute household feeding inputs away from a school-going child towards other family members.

In addition to our main treatment effects, we explore each of the issues raised above. First, we explore enrollment effects of the program and, in a a simple accounting exercise, examine to what extent the learning effect can be attributed to a pure nutrition-learning channel. Second, we explore the role of complementary teaching inputs in determining the efficacy of the midday meal scheme in improving learning. Third, we examine heterogeneous treatment effects based on gender and housing assets. Finally, we investigate whether children who are exposed to the program and live in households whose composition makes them more likely to engage in intra-family redistribution-because they are larger, or the child has siblings_-also have more muted test score improvements.

The Indian context we study is important for two reasons. First, the learning deficit in primary schools is large. An ASER (2005) report, for example, shocked the Indian public with the revelation that 44\% of children between the ages of 7 and 12 who were actually enrolled in school could not read a basic paragraph and 50\% could not do simple subtraction. Second, the scale of the intervention is massive: India's midday meal scheme is the largest school nutrition program in the world. In 2006, it provided lunch to 120 million children in government primary schools on every school day (Kingdon, 2007). To put this number in perspective, it accounts for a staggering one third of children globally who, according to the WFP (2013), enjoy school feeding programs.

In order to identify the causal effect of this program, we exploit its staggered implementation. Briefly, and in more detail later, a 2001 Indian Supreme Court directive ordered Indian states to institute free midday meals in government primary schools. Prior to 2001 only two states, Tamil Nadu and Gujarat, had universal public primary school midday meal provision. Over the subsequent five years, however, state governments across India introduced midday meals. Staggered implementation of the program in primary schools generates variation in the length of exposure to the program based on a child's birth cohort and state of residence. Children only enjoyed the program to the extent that they were of primary-school going age - 6 to 10 years old—and lived in a state which had instituted midday meals in primary school. Hence, the earlier their state introduced the program and the young enough they 
were at the time, the longer was the child's potential exposure to midday meals, in this intent-to-treat (ITT) framework.

Our data come from the Annual Status of Education Report (ASER) survey, whose goal is to assess the state of education among children in India. It has three unique features that are useful for the purpose of this analysis. First, it has remarkably wide geographic coverage, surveying over 200,000 households in each of India's roughly 580 rural districts. Second, it has been administered annually since 2005. Third, ASER administers learning assessments of basic literacy (reading skills) and numeracy (number recognition and arithmetic skills) to all children aged 5 to 16 . These features allow us to capture variation in exposure to treatment across states and time, while correcting for state- and cohort-specific effects as well as state-specific time trends, in order to assess the program's effect on learning. State fixed effects allow for average test scores to vary across different states, accounting for the possibility that children in better (or worse) performing states may have longer program exposure because their states implemented the program earlier (or later). Cohort fixed effects address the concern that older children are likely to have higher test scores than younger children, and also potentially have longer program exposure. Finally, the inclusion of state-specific time trends permits for trends in average test performance to vary from state to state. The key identifying assumption in this context is parallel trends in test performance across states within cohorts.

We find that exposure to midday meals increases students' learning achievement, albeit at a decreasing rate. Students with up to five years of exposure have reading test scores that are $18 \%(0.17$ standard deviations) higher than students with less than a year of exposure. The corresponding increase for math test scores is a more modest, but still sizable 9\% (0.09 standard deviations). An accounting exercise allows us to put an upper bound on the pure nutrition effect of this program which, assuming that newly enrolled children experience no change in test scores, lies at 0.18 standard deviations for reading and 0.13 standard deviations for math. When we explore complementarities, we find that schooling inputs that are directly related to teaching are associated with significantly higher learning when combined with the midday meal, but more more general schooling infrastructure is not. At the same time, we find no evidence of heterogeneous treatment effects on the basis of gender or housing assets. Finally, we find limited evidence of intra-household redistribution from eligible children to other family members.

We also run a series of robustness checks that ascertain the veracity of our main finding. First, we examine whether our results are robust to the inclusion of schooling inputs, which capture potentially confounding changes that may account for test score improvements. Second, we consider alternative measures of test performance to account for potential measurement error in the raw test score. Third, we extend our main sample from 6-10 year-olds to 5-11 year-olds, which allows for a wider range of potential program exposure. Fourth, we account for potential unobserved heterogeneity at the family level by estimating household fixed effects. Fifth, we explore to what extent the timing of implementation influences our result by considering alternative samples based on the date of program implementation. Finally, we estimate ordered logit and probit models to verify that our result is not an artifact of the more easily interpretable OLS estimator that we use elsewhere in the paper.

There is a substantial literature on the effect of school feeding programs on school participation and nutritional outcomes; see Alderman and Bundy (2012) for an excellent review. Most of these studies have focused on young, typically primary-school-aged children, and have generally found 
that there are positive treatment effects on both participation (e.g. higher enrollment or attendance) and nutritional status (e.g. lower anemia, lower morbidity, higher BMI). ${ }^{1}$

The focus of this paper is to examine the effects of school feeding on learning achievement. It speaks to two main strands of this literature: one that uses randomized controlled trials to examine the effect of school feeding programs on cognitive achievement, and another which explores the effect of India's midday meal program on schooling outcomes. We make three main contributions to the literature. First, we employ a large scale survey to examine a nationwide school feeding program, with what we hope is careful attention to identification. Second, we look at the effects of long-term program exposure. Third, we examine a number of potential channels that may account for improvements in learning achievement.

Numerous studies have examined the effect of school feeding programs on learning achievement in the context of small-scale, relatively short-term, randomized field experiments. ${ }^{2}$ These field experiments find that school feeding programs, at best, improve cognitive performance for a subset of students on a subset of tasks. After a year-long randomized school feeding intervention in Burkina Faso, Kazianga et al. (2012) finds no significant effect on cognitive tests, including Raven's Progressive Matrices and digit span tests; the main positive finding is that girls (though not boys) took significantly less time to answer arithmetic questions. After a year-long randomized school breakfast intervention in Jamaica, Powell et al. (1998) find no significant improvements in spelling or reading, and significant improvements in arithmetic only in younger children. In a year-long randomized intervention providing South African children with fortified biscuits, Van Stuijvenberg et al. (1999) finds positive average treatment effects on only one of nine cognitive tasks (namely, forward digit span), but improvements on more dimensions for children with low baseline nutritional status. In a five-week breakfast experiment in Jamaica, Grantham-McGregor et al. (1998) similarly find a significant positive effect on cognitive function only among undernourished children. In a randomized intervention lasting two years in Uganda, Adelman et al. (2008) find no effect of school feeding (or take home rations) on math or literacy scores, although there is a positive math test score effect for the 11-14 age group.

In a two-year randomized intervention, Neumann et al. (2007) find that mid-morning school snacks in Kenya resulted in improved cognitive function as measured by Raven's Progressive Matrices scores as well as arithmetic test performance, but find no differences in terms of tests of verbal meaning or digit span. Kremer and Vermeersch (2004) find that a randomized preschool breakfast program in Kenya that lasted approximately two years did not improve curriculum test scores in schools unless teachers were relatively experienced. Finally, Whaley et al. (2003) find that in a two-year Kenyan

\footnotetext{
${ }^{1}$ See, for example, Jacoby et al. (1998) in Peru, Powell et al. (1998) in Jamaica, Van Stuijvenberg et al. (1999) in South Africa, Jacoby (2002) in the Philippines, Neumann et al. (2003) in Kenya, and Bhattacharya et al. (2006) in the US find generally positive effects of school feeding programs on children's health and nutritional status. Jacoby et al. (1998) in Peru, Powell et al. (1998) in Jamaica, Ahmed (2004) in Bangladesh, Kremer and Vermeersch (2004) in Kenya, Belot and James (2011) in the U.K., Kazianga et al. (2012) in Burkina Faso find positive effects of school feeding programs on school participation.

${ }^{2}$ In a rare non-randomized evaluation of an extant national program, McEwan (2013) uses a regression discontinuity design to study the effect of Chile's long-established school feeding program on (among other things) fourth-grade test scores. The discontinuity comes from the fact that students received meals with different caloric content depending on a school-level "vulnerability" index cutoff. McEwan (2013) finds that there is no difference in test performance when the caloric content of meals is increased.
} 
intervention with three different feeding interventions plus a pure control group, only the meat supplement treatment arm showed significant gains in Raven's Progressive Matrices while children in the supplemental energy and milk groups displayed no improvement.

The midday meal program itself has been widely reviewed in policy circles by Indian government and non-government organizations such as the Planning Commission, the National Institute of Public Cooperation \& Child Development, and the Centre for Environment and Food Security. These studies are unanimous in their agreement that the midday meal program has helped increasing attendance and enrollment of children; see MHRD (a) for an overview of this evidence. A few report higher learning ability based on teacher feedback. While these policy reviews are informative, they are tend to be descriptive in nature and lack clear identification strategies.

A handful of recent studies have examined the effect of midday meals in India on school participation and nutritional outcomes, with more careful attention to identification. In Madhya Pradesh Afridi (2010) finds, using a difference-in-differences approach, that children provided with midday meals experienced sizable improvements in nutrient intake and reductions in protein and calorie deficiency. In Andra Pradesh Singh et al. (2014) find, using IV methods, that midday meals compensated for the negative effects of drought on nutritional status. In terms of school participation, Afridi (2011) finds no impact of midday meals on enrollment, but a positive effect on attendance among girls. Using a large administrative data set from 13 states, Jayaraman and Simroth (2015) find substantial enrollment effects of the program in its initial three years.

Only two small-scale studies have examined the effect of midday meals on learning outcomes using variation at the local level. Singh (2008) finds improvements in Peabody Picture Vocabulary Tests in the Young Lives panel of about 500 children in Andhra Pradesh. However, he is cautious in the interpretation of this result since he lacks a control group in the analysis. Afridi et al. (2014) use the extension of midday meals to upper primary school (grades 6-8) in educationally "backward" localities to evaluate the effect of midday meals on learning outcomes of 400 students in 16 Delhi schools using difference-in-differences. The authors find a significant improvement in classroom attention, using the ability of children to solve puzzles although, in the 4-month time frame of their study, they find no improvement in academic test scores.

Our paper adds to this literature in three main ways. First, we use a large dataset. This not only affords us statistical power, but also allows us to study an intervention that has been implemented on a massive scale: it is the largest such program in the world and accounts for a third of all children who enjoy school feeding programs. The fact that the intervention is in no way "gold-plated", combined with our use of a large data set that is representative of rural India also arguably adds to the generalizability of our findings. The obvious drawback is that, since this is an extant program, we need to resort to quasi-experimental rather than experimental methods for identification. Our main identifying assumption is that there are parallel trends in learning achievement within cohorts between early and late program implementers. While the descriptive analysis suggests that the stronger assumption of parallel trends in average outcomes between early and late implementers is plausible, and our results are robust to a number of specification checks pertaining to the timing of implementation, we cannot formally test this assumption.

The second contribution of this paper is that we are able to examine the effects of much longer-term exposure than others have to date, since children are exposed to the the program for up to five yearsthe duration of primary school in India. Finally, in addition to first-order effects on learning, we 
explore four channels which may account for it: enrollment and nutrition-learning effects, complementary schooling inputs, heterogeneous effects by gender and housing assets, and intra-household redistribution.

In contrast to most of the extant literature, we find an unambiguously positive effect of school feeding, measured by both arithmetic and reading tests. There are three likely explanations for this. First, the gains that we observe due to long term exposure may not be fully captured in many of the shorterterm interventions that have been evaluated to date. Indeed, we see some evidence of this in our data, where improvements in math test scores are not evidenced until after the second year of exposure. Second, our data come from villages in rural India where nutritional deficiency is a chronic problem. Using National Sample Survey (NSS) data, Deaton and Drèze (2009) calculate that in 2004-5-the first year of observation in our data-almost $80 \%$ of the rural population lived in households with a per capita calorie consumption below the rural poverty line of 2,400 . In is conceivable that the sizable gains in learning achievement that we find reflects the fact that the target population of this intervention in our sample is extremely nutritionally disadvantaged to begin with. This would be in line with the findings of Powell et al. (1998), Van Stuijvenberg et al. (1999) and Grantham-McGregor et al. (1998) summarized above. It is also consistent with the fact that we find no heterogeneous treatment effects in terms of gender or household assets, in that the bulk of children in our data are likely to suffer from substantial economic disadvantage. Finally, small sample sizes may account for imprecise estimates of positive effects in earlier studies. Our large dataset allows us to evade this problem.

The rest of the paper is organized as follows. Section 2 furnishes the policy background. Section 3 describes our data and empirical model. The main result - the effect of midday meals on test scoresis presented in Section 4. Section 5 provides a deeper understanding of the channels which drive the increase in test scores. Section 6 describes a series of robustness checks on our main result from Section 4, and Section 7 concludes.

\section{Policy BACKGRound}

The Indian central government has a long-standing commitment to on-site school feeding programs. In 1995, the central government mandated free cooked meals in all public primary schools via the National Program of Nutritional Support to Primary Education. In India, the central government's role in school education lies in issuing policy guidelines and providing funding; by contrast, policy implementation is the prerogative of state governments. Not a single state responded to this universal mandate. ${ }^{3}$

Half a decade later, India witnessed a sea change. In early 2001 there was a severe drought in 7 districts, to which the press and many civil society organizations attributed a number of starvation

\footnotetext{
${ }^{3}$ Kerala responded with an opt-in program for public primary schools, leading to partial coverage. Tamil Nadu's and Gujarat had, in 1982 and 1984 respectively, already instituted universal primary school midday meal programs. Most other states provided "dry rations" to enrolled children who attended school, which typically comprised $3 \mathrm{~kg}$. per month of raw wheat or rice grains (depending on local consumption habits). By many accounts, the distribution of these dry rations was sporadic, of low quality and conditional attendance requirements went unenforced (see for example PROBE (1999)). Moreover, there is evidence of extensive leakage in this dry rations program (see for example Muralidharan (2006)).
} 
deaths. ${ }^{4}$ In April, 2001 the People's Union for Civil Liberties (PUCL) took the government of India to court, arguing in its writ petition that, "while on the one hand the stocks of food grains in the country are more than the capacity of storage facilities, on the other there are reports from various states alleging starvation deaths." " The PUCL documented that it was perfectly feasible for the government to widen a number of statutory food and nutrition programs, including the moribund midday meal scheme in schools. In response to this petition, on November 28, 2001, the Indian Supreme Court issued an interim order stating that "Every child in every government and government-assisted school should be given a prepared midday meal". ${ }^{6}$

Implementation of this and other Supreme Court orders lies in the hands of the relevant executive branch of government, which in this instance was state governments (Desai and Muralidhar, 2000). Midday meal implementation did not take place immediately or all at once, but over the next 5 years states across India implemented the program until, by 2006, every Indian state had instituted a free school lunch in primary schools. Table 1 documents the month and year of policy implementation in the 24 states and union territories used in our main analysis. Tamil Nadu, Gujarat, Puducherry and Kerala are excluded from this sample since their program implementation preceded the 2001 mandate, but we show in robustness checks that their inclusion does not alter our results. The table as well as the map in Appendix Figure A1, which depicts implementation years graphically, shows that there is considerable variation in the timing of implementation across different states. As explained in the following section, this variation will be central to our identification strategy.

In keeping with standard education policy practice, most of the funding for midday meals comes from the central government. During our observation period from 2005-2012, the central government provided financial assistance to cover the cost and transport of food grains, as well as cooking costs. This is supplemented to varying degrees by state governments in a manner that is non-transparent and poorly documented. Hence in what follows we describe central government funding provisions. ${ }^{7}$ Food grains are provided by the Food Corporation of India (FCI), an institution set up in 1964 to support the operation of the central government's food policies. Midday meal guidelines stipulate that each student be provided 100 grams of wheat or rice, 20 grams of pulses, 50 grams of vegetables and 5 grams of fat per day, amounting to a targeted total of 300 kilo calories and 8-12 grams of protein (MHRD, b). This cost approximately Rs. 2.5 per student per day, including cooking costs. In addition to the direct cost of food, the cost of labor and management, which include salaries paid to cooks and helpers, adds another Rs.0.40, for a total cost of food equal to Rs. 2.90 per child per day as per the 2009 guidlines. Of this, the central government provides Rs 2.17 and states are left to bear the remaining Rs. $0.63 .^{8}$

\footnotetext{
${ }^{4}$ There were 7 drought-affected states in 2001: Gujarat, Rajasthan, Maharashtra, Orissa, Madhya Pradesh, Chhattisgarh, and Andhra Pradesh (Down to Earth, Vol. 10, Issue 20010615, June 2001). They include both early and late implementers of midday meals.

${ }^{5}$ Rajasthan PUCL Writ in Supreme Court on Famine Deaths, PUCL Bulletin, November 2001.

${ }^{6}$ Supreme Court Order of November 28, 2001, Record of Proceedings Writ Petition (Civil) No. 196 of 2001.

${ }^{7}$ Available evidence suggests that there is no obvious correlation between supplements and timing of midday meal implementation. For example, Andhra Pradesh (which implemented in 2003) contributed Rs. 1 per child per day towards cooking costs in 2005, whereas Rajasthan and Chattisgarh, which implemented earlier than Andra Pradesh, contributed little towards cooking costs (Secretariat of the Right to Food Campaign, 2005).

${ }^{8}$ The figures quoted here reflect the cost for India excluding the North Eastern States. In the case of North Eastern States, the central government bears a higher fraction of the total costs.
} 


\begin{tabular}{lrc}
\hline State & Implementation \\
& Month & Year \\
\hline Andhra Pradesh & January & 2003 \\
Arunachal Pradesh & July & 2004 \\
Assam & January & 2005 \\
Bihar & January & 2005 \\
Chhattisgarh & April & 2002 \\
Dadar \& Nagar Haveli & February & 2002 \\
Daman \& Diu & June & 2003 \\
Haryana & August & 2004 \\
Himachal Pradesh & September & 2004 \\
Jammu \& Kashmir & April & 2005 \\
Karnataka & July & 2003 \\
Madhya Pradesh & January & 2004 \\
Maharashtra & January & 2003 \\
Manipur & November & 2004 \\
Meghalaya & January & 2003 \\
Mizoram & February & 2006 \\
Orissa & September & 2004 \\
Punjab & September & 2004 \\
Rajasthan & July & 2002 \\
Sikkim & October & 2002 \\
Tripura & April & 2003 \\
Uttar Pradesh & September & 2004 \\
Uttranchal & July & 2003 \\
West Bengal & March & 2005 \\
\hline Miday Mea & anplent &
\end{tabular}

Table 1. Timing of States' Midday Meal Implementation Notes. The states listed in this table are all included in the main sample. States available in ASER but excluded from the main sample due to lack of information regarding when the scheme was introduced: Jharkhand \& Nagaland. States or union territories excluded from the main sample due to implementation prior to the mandate under study: Kerala, Gujarat, Kerala, Pondicherry and Tamil Nadu. The month and year of midday meal policy implementation were collected from state midday meal scheme audit and budget reports.

The central government further provides a transport subsidy to carry grains from the nearest FCI warehouse to the primary school, up to a maximum of Rs. 75 per quintal, amounting to an average transport subsidy of Rs. 0.075 per child per school day. An additional budget of approximately $2 \%$ of total cost is assigned by the central government for the management, monitoring and evaluation of the program, amounting to an additional Rs 0.045 per child per day. The total value of the central government subsidy therefore amounted to Rs. 2.30, or approximately 5 U.S. cents as per the October 2009 exchange rate, per child per school day. ${ }^{9}$

While the overall responsibility for program implementation lies with state governments, day-to-day operations lie in the hands of local government bodies, typically village governments (panchayats),

\footnotetext{
${ }^{9}$ We use the approximate exchange rate as of December 2009 to match with the reference date of the cost estimates.
} 
who sometimes delegate implementation to local Parent Teacher Associations (PTAs) or NGOs. The meal itself is not extravagant. It is cooked at schools by cooks and their helpers, who are hired for this purpose. At around noon, children are served cooked rice or wheat, depending on the local staple, mixed with lentils or jaggery, and sometimes supplemented with oil, vegetables, fruits, nuts, eggs or dessert at the local level. The menu varies from place to place, but anecdotal evidence suggests that children generally enjoy the opportunity to sit with their peers and eat their midday meals (see, for example, Drèze and Goyal (2003)).

\section{DATA AND EMPIRICAL STRATEGY}

3.1. Data. Our data come from the Annual Status of Education Report (ASER), a yearly survey devoted to documenting the status of education among children in rural India. Annual household surveys began in 2005, and have been conducted ever since by a motley crew of over 700 NGOs and local institutions under the banner of Pratham, an NGO that specializes in education in India. The data comprise a repeated cross-section. Each year, the survey is conducted around October, and covers a random sample of 20-30 households per village in 20 villages in each of India's roughly 580 rural districts.

What makes ASER truly unique is that it tests all children in the household between the ages of 5 and 16 for reading and math proficiency using rigorously developed testing tools. The fact that the survey is administered in households rather than in schools is useful because it enables an assessment of learning outcomes regardless of school participation. Figures 1 and 2 depict the tests ASER administers for reading and math, respectively. These are English language examples; in practice these tests are administered in vernacular languages. The reading assessment has 4 levels of mastery: letters, words, a short paragraph (grade 1 level text), and a short story (grade 2 level text). Similarly, the math assessment consists of four levels: single-digit number recognition, double-digit number recognition, two-digit subtraction with carry over, and three digit by one digit division. For both tests separately, the child is marked at the highest level he or she can do comfortably with scores ranging from 0 to 4 . A score of 0 means that the child cannot do even the most basic level and a score of 4 means that he or she can do level 4 in the respective subject.

We use data from all 8 available household cross-sections, from 2005-2012. Since the policy mandate covered public primary schools, we restrict our attention to all primary school-aged children who are either not enrolled in school, or go to public schools. In India, primary school typically runs from grade 1 to grade 5 and officially corresponds to children aged 6-10. The rationale for this sample age restriction was twofold. First, the Supreme Court mandate pertained to primary schools, which cover precisely this age group. Second, some localities offer feeding programs to younger children, in "Angawadis" that care for preschool children, or older children in secondary schools. While there is no systematic pattern across states in these offerings, including younger and older children in the sample would run the risk of "mis-allocation" of children to the control group when, in fact, they received a school feeding program. We show in robustness checks that extending the sample to include 5-11 year-olds does not change the results.

We further restrict our attention to the states listed in Table 1, which were subject to the Supreme Court mandate; in additional robustness checks, we add earlier implementers. Altogether, our main sample of 6-10 year olds comprises roughly 1.25 million children in 24 states and union territories, averaging about 150,000 observations in each cross section; see Table 2. Appendix Table A1, which 

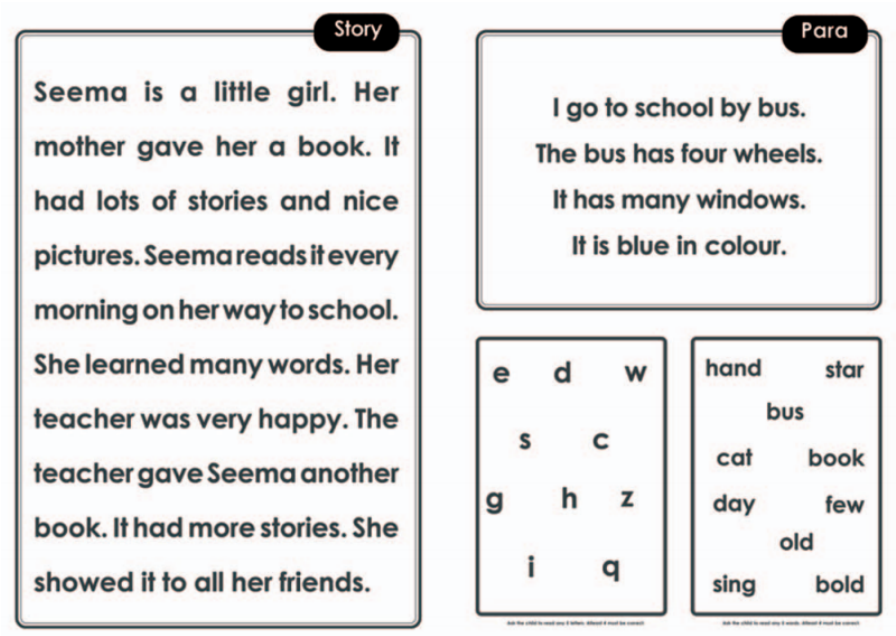

Figure 1. ASER Reading Test.

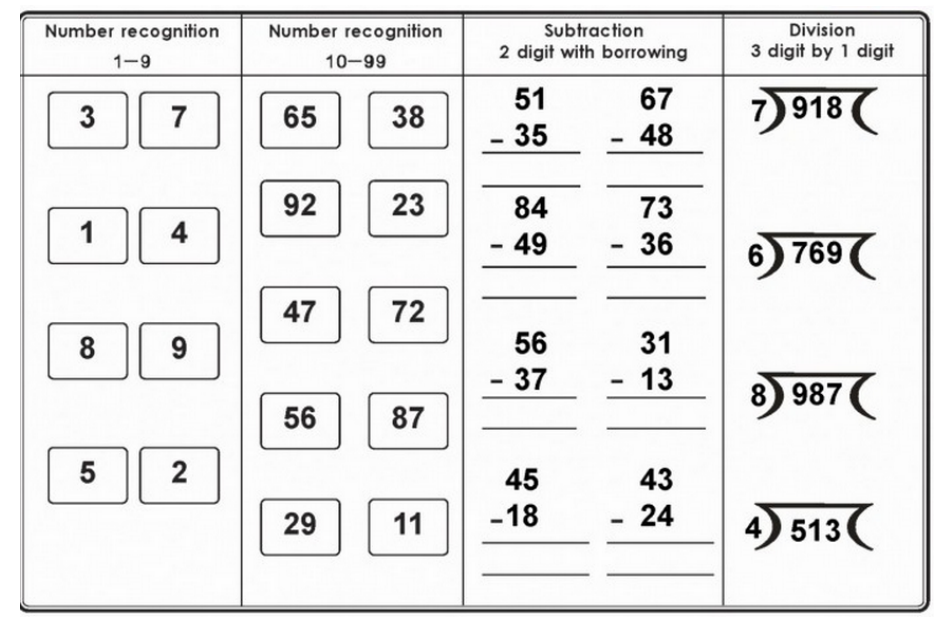

Figure 2. ASER Math Test.

shows a breakdown of the number of observations by state-year, demonstrates the rich temporal and geographic coverage of the data. State-wise sample sizes obviously vary, reflecting their differing populations, but robustness checks in which we drop states one-by-one indicate that no one state is driving our results.

Table 2 furnishes summary statistics for each of the 8 survey years. The first two rows denote average reading and math scores. These scores measure learning achievement and will be the main outcomes of interest in our empirical analysis. The scores take integer values ranging from 0 (inability to do even the most basic level) to 4 (mastery of the highest level). The average scores for both reading and math hover at around 2 during the observation period, reflecting the dismal state of learning in Indian schools. Concretely, a 2 means that on average, primary school-aged children can read words but not a class 1 level paragraph or class 2 level story; they can recognize double digit numbers but cannot do two digit subtraction or divide a 3 digit number by a 1 digit number. 
SCHOOL FEEDING AND LEARNING ACHIEVEMENT: EVIDENCE FROM INDIA'S MIDDAY MEAL PROGRAM 11

\begin{tabular}{|c|c|c|c|c|c|c|c|c|c|}
\hline & \multicolumn{9}{|c|}{ Survey Year } \\
\hline & 2005 & 2006 & 2007 & 2008 & 2009 & 2010 & 2011 & 2012 & Overall \\
\hline Reading Score & $\begin{array}{c}2.045 \\
(1.468)\end{array}$ & $\begin{array}{c}2.050 \\
(1.394)\end{array}$ & $\begin{array}{c}2.198 \\
(1.331)\end{array}$ & $\begin{array}{c}2.144 \\
(1.359)\end{array}$ & $\begin{array}{c}2.209 \\
(1.311)\end{array}$ & $\begin{array}{c}2.175 \\
(1.317)\end{array}$ & $\begin{array}{c}1.958 \\
(1.354)\end{array}$ & $\begin{array}{c}1.796 \\
(1.399)\end{array}$ & $\begin{array}{c}2.089 \\
(1.369)\end{array}$ \\
\hline Math Score & $\begin{array}{c}1.911 \\
(1.424)\end{array}$ & $\begin{array}{c}2.059 \\
(1.401)\end{array}$ & $\begin{array}{c}2.060 \\
(1.243)\end{array}$ & $\begin{array}{c}1.959 \\
(1.246)\end{array}$ & $\begin{array}{c}2.077 \\
(1.231)\end{array}$ & $\begin{array}{c}2.004 \\
(1.214)\end{array}$ & $\begin{array}{c}1.772 \\
(1.193)\end{array}$ & $\begin{array}{c}1.606 \\
(1.158)\end{array}$ & $\begin{array}{c}1.954 \\
(1.279)\end{array}$ \\
\hline Enrollment & $\begin{array}{c}0.956 \\
(0.206)\end{array}$ & $\begin{array}{c}0.942 \\
(0.234)\end{array}$ & $\begin{array}{c}0.974 \\
(0.159)\end{array}$ & $\begin{array}{c}0.969 \\
(0.174)\end{array}$ & $\begin{array}{c}0.974 \\
(0.160)\end{array}$ & $\begin{array}{c}0.979 \\
(0.144)\end{array}$ & $\begin{array}{c}0.979 \\
(0.144)\end{array}$ & $\begin{array}{c}0.979 \\
(0.142)\end{array}$ & $\begin{array}{c}0.968 \\
(0.176)\end{array}$ \\
\hline Dropout & $\begin{array}{l}0.0124 \\
(0.111)\end{array}$ & $\begin{array}{l}0.0115 \\
(0.107)\end{array}$ & $\begin{array}{c}0.00969 \\
(0.0980)\end{array}$ & $\begin{array}{c}0.00936 \\
(0.0963)\end{array}$ & $\begin{array}{c}0.00768 \\
(0.0873)\end{array}$ & $\begin{array}{c}0.00685 \\
(0.0825)\end{array}$ & $\begin{array}{c}0.00545 \\
(0.0736)\end{array}$ & $\begin{array}{c}0.00557 \\
(0.0744)\end{array}$ & $\begin{array}{l}0.00877 \\
(0.0932)\end{array}$ \\
\hline Never Enrolled & $\begin{array}{l}0.0320 \\
(0.176)\end{array}$ & $\begin{array}{l}0.0463 \\
(0.210)\end{array}$ & $\begin{array}{l}0.0162 \\
(0.126)\end{array}$ & $\begin{array}{l}0.0218 \\
(0.146)\end{array}$ & $\begin{array}{l}0.0185 \\
(0.135)\end{array}$ & $\begin{array}{l}0.0142 \\
(0.118)\end{array}$ & $\begin{array}{l}0.0158 \\
(0.125)\end{array}$ & $\begin{array}{l}0.0151 \\
(0.122)\end{array}$ & $\begin{array}{l}0.0231 \\
(0.150)\end{array}$ \\
\hline Age & $\begin{array}{c}8.159 \\
(1.424)\end{array}$ & $\begin{array}{c}8.150 \\
(1.434)\end{array}$ & $\begin{array}{c}8.178 \\
(1.404)\end{array}$ & $\begin{array}{c}8.178 \\
(1.412)\end{array}$ & $\begin{array}{c}8.224 \\
(1.414)\end{array}$ & $\begin{array}{c}8.224 \\
(1.408)\end{array}$ & $\begin{array}{c}8.186 \\
(1.413)\end{array}$ & $\begin{array}{c}8.171 \\
(1.407)\end{array}$ & $\begin{array}{c}8.184 \\
(1.415)\end{array}$ \\
\hline Female & $\begin{array}{c}0.460 \\
(0.498)\end{array}$ & $\begin{array}{c}0.466 \\
(0.499)\end{array}$ & $\begin{array}{c}0.467 \\
(0.499)\end{array}$ & $\begin{array}{c}0.475 \\
(0.499)\end{array}$ & $\begin{array}{c}0.466 \\
(0.499)\end{array}$ & $\begin{array}{c}0.468 \\
(0.499)\end{array}$ & $\begin{array}{c}0.481 \\
(0.500)\end{array}$ & $\begin{array}{c}0.495 \\
(0.500)\end{array}$ & $\begin{array}{c}0.471 \\
(0.499)\end{array}$ \\
\hline $\begin{array}{l}\text { Household } \\
\text { Size }\end{array}$ & $\begin{array}{c}7.337 \\
(4.226)\end{array}$ & $\begin{array}{c}7.818 \\
(4.643)\end{array}$ & $\begin{array}{c}6.691 \\
(3.493)\end{array}$ & $\begin{array}{c}6.834 \\
(3.142)\end{array}$ & $\begin{array}{c}6.436 \\
(2.803)\end{array}$ & $\begin{array}{c}6.414 \\
(2.848)\end{array}$ & $\begin{array}{c}6.590 \\
(3.075)\end{array}$ & $\begin{array}{c}6.728 \\
(3.247)\end{array}$ & $\begin{array}{c}6.874 \\
(3.550)\end{array}$ \\
\hline Exposure in Months & $\begin{array}{c}15.00 \\
(9.595)\end{array}$ & $\begin{array}{c}20.51 \\
(11.26)\end{array}$ & $\begin{array}{c}26.31 \\
(13.53)\end{array}$ & $\begin{array}{c}29.01 \\
(15.78)\end{array}$ & $\begin{array}{c}30.65 \\
(16.93)\end{array}$ & $\begin{array}{c}30.69 \\
(16.90)\end{array}$ & $\begin{array}{c}30.23 \\
(16.95)\end{array}$ & $\begin{array}{c}30.05 \\
(16.88)\end{array}$ & $\begin{array}{c}26.49 \\
(15.73)\end{array}$ \\
\hline Exposure in Years & $\begin{array}{c}0.717 \\
(0.961)\end{array}$ & $\begin{array}{c}1.259 \\
(0.961)\end{array}$ & $\begin{array}{c}1.784 \\
(1.100)\end{array}$ & $\begin{array}{c}2.042 \\
(1.274)\end{array}$ & $\begin{array}{c}2.221 \\
(1.411)\end{array}$ & $\begin{array}{c}2.224 \\
(1.408)\end{array}$ & $\begin{array}{c}2.186 \\
(1.413)\end{array}$ & $\begin{array}{c}2.171 \\
(1.407)\end{array}$ & $\begin{array}{c}1.818 \\
(1.338)\end{array}$ \\
\hline No. Observations & 125,960 & 184,628 & 198,321 & 173,711 & 162,829 & 149,564 & 132,768 & 111,000 & $1,238,781$ \\
\hline
\end{tabular}

Table 2. Summary Statistics by Survey Year Notes. Each cell in this table contains means, with standard deviations in parentheses.

In addition to administering these tests, ASER collects information regarding the child's current school participation as well as some basic demographic information pertaining to the child's age in years, gender and household size. Consistent with official estimates, net enrollment remains at a pretty steady $97 \%$ during the observation period. Among out-of-school children, approximately one-third are dropouts and two-thirds have never enrolled in school. The average age of children in our sample is around 8. Just under half are female, and the average household size is roughly 7.

3.2. Empirical Strategy. The main objective of this paper is to estimate the causal effect of potential midday meal exposure on test scores. We accomplish this by exploiting the fact that the 2001 Supreme Court mandate was implemented in pubic primary schools in a staggered manner across Indian states between 2002 and 2006. This means that a child's exposure to the program is jointly determined by 
her year of birth and the timing of midday meal introduction in her state: only a child who was 6-10 after midday meals were introduced in her state, was partially exposed to the program.

To see how birth year and timing of implementation generate variation in potential program exposure, consider the following example. Take Andhra Pradesh, which introduced the program in 2003. A child who was born in 1994 in Andhra Pradesh was 8 years old in 2002, so she was potentially exposed to the program; a child born in 1990, was already 12 by 2003 and was therefore not exposed to the program; and a child born in 1995 was exposed to the program throughout primary school.

Of course, it would be problematic if exposure only varied by birth cohort, since older children are likely to do better in tests than younger children. Staggered implementation allows us to control for cohort-specific performance because it induces variation in program exposure within birth cohorts. To see how, consider two children: Gayatri from Andhra Pradesh, and Jai from Rajasthan. Both children were born in 1994. However, since Andhra Pradesh implemented the program in 2003 and Rajasthan implemented in 2002, Jai has more program exposure than Gayatri.

The examples above serve to illustrate our how staggered implementation generates variation in years of exposure. In fact, since different states introduced the program in different months, we have variation in months rather than simply years of exposure. The Indian school year typically starts in June and children are officially supposed to be enrolled in grade 1 in the year they turn 6 . The ASER survey is conducted in September-November each year. The precise month varies and is not systematically recorded, so we take the median, October, which is when most surveys are conducted. Depending on the month and year of program implementation a child can in principle have anywhere between 0 (if the program was implemented just after the test was administered for a 10 year-old) and 52 months (if the child is 10 years old and has had 4 full years of exposure plus 4 months in grade 5 from June, when the academic year starts, to October when the test is administered) of program exposure. Appendix Table A6 provides a detailed description of how we construct the months of exposure variable based on a child's current age and her age at the time of midday meal introduction.

The bottom rows of Table 2 show that on average, children in the sample have 26 months, or roughly 2 years, of policy exposure. This is obviously lower for earlier survey years given that the policy was implemented between 2002 and 2006. We will account for this difference in our empirical analysis by including survey year fixed effects.

Figure 3, which presents a scatter plot of months of potential exposure against birth year, demonstrates that there is considerable variation in our data along both these dimensions. Three remarks on this figure are in order. First, all the children in our sample have at least 4 months of program exposure. This follows from the fact that ASER commenced its surveys in 2005 after all major states had already instituted the program. Second, as the megaphone-like shape of the data indicates, older and younger children tend to have less exposure than others. We account for this in our empirical analysis by accounting for birth year. Third, there is a natural "lumpiness" in the data at $4,16,28$, 40 and 52 months of exposure. Each of these months contain between 14-22\% of the children in the main sample. This follows from the fact that the survey was conducted 4 months after the school year commences. So, for example, a 6-year-old child will have had 4 months of potential exposure if the program was instituted before June of the current year, a 7-year old child will have had 16 months of exposure if it was instituted before June of the previous year, and so forth; this can be seen clearly upon examination of row 1 of Appendix Table A6. We start the empirical analysis by exploiting variation in months of exposure. However, in order to account for the lumpiness in the data and reduce 


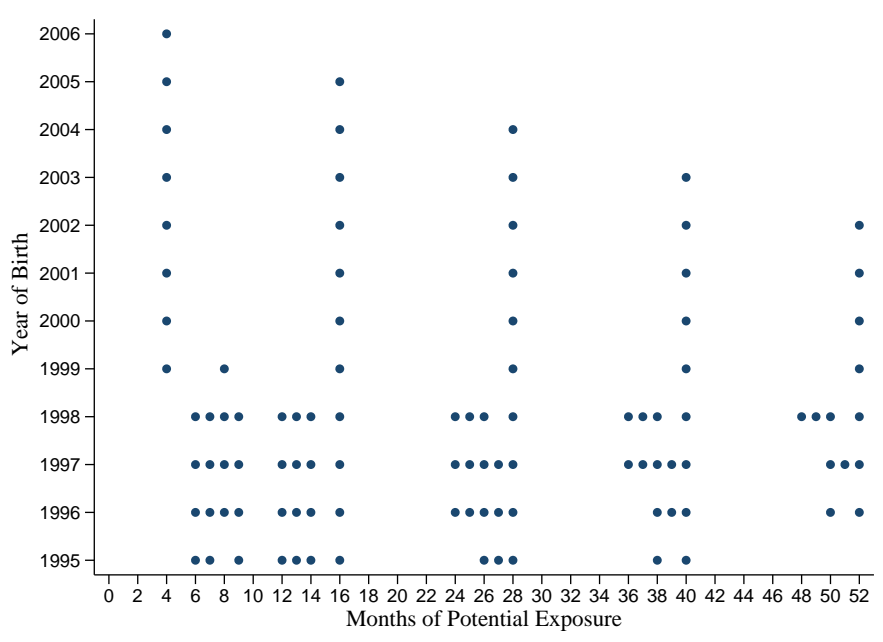

Figure 3. Variation in Months of Potential Exposure by Birth Year. Notes: This graph depicts the variation in our data in months of exposure (x-axis) by birth year (y-axis).

the potential for measurement error, we also report results by years of exposure and show that this does not alter our qualitative results.

We begin by estimating the following baseline model, which exploits variation in months of program exposure generated by a child's age and timing of policy introduction in his or her state:

$$
y_{i t c s}=\alpha+\beta \cdot \text { Exposure }_{i(t c s)}+\phi \text { Controls }_{i t c s}+\delta_{t}+\delta_{c}+\delta_{s}+\gamma_{s} t+\varepsilon_{i}
$$

where $y_{i c s t}$ measures the reading or math test score of child $i$, surveyed in year $t$, belonging to birth cohort $c$, and residing in state $s$. The Exposure variable captures captures months of potential program exposure. In principle, this could vary anywhere from 0 months if the child has never been exposed to the program, and 60 months, for children who have the full 5 years of exposure all through primary school. In these data, it varies between 4 and 52 months. Our parameter of interest is $\beta$ : it captures the treatment effect of exposure to midday meals on test scores. Controls variables include gender, household size and a dummy variable for whether or not the child's mother attended school. The parameters $\delta_{t}$ capture $\delta_{c}$ and $\delta_{s}$ account for differences in test outcomes by time (i.e. survey year), birth cohort, and state, respectively. The $\gamma_{s}$ is a linear state-specific time trend, which allows for the linear evolution of test scores over time to vary by state.

This empirical specification allows us to control for any systematic shocks to outcomes, which are correlated with but not attributable to program exposure across three dimensions. First, survey timing (captured through $\delta_{t}$ ) is important because there may be natural variation in test scores over time and, as we see in Table 2, children surveyed in earlier years naturally have lower levels of program exposure given that midday meals were implemented between 2002 and 2006. Second, cohort effects $\left(\delta_{c}\right)$ are relevant because it is natural to expect older children to have more exposure than younger children and perform better in these tests. Third, differences across states are pertinent because, although there is remarkable variation in their timing of implementation-for example, early implementers include both economically advanced states such as Andhra Pradesh and Karnataka and laggards such as Rajasthan and Uttranchal-it also seems plausible that early implementers may have systematically 
different schooling outcomes than late implementers. Including state fixed effects $\left(\delta_{s}\right)$ captures this difference.

We may still worry that the timing of implementation is correlated with trends in test scores. State specific time trends (captured through $\gamma_{s}$ ) account for this possibility in part. Unfortunately, because all the children in our sample have some program exposure, we cannot examine whether children in early and late implementing states have parallel trends in test scores prior to program exposure. ${ }^{10}$ The closest we can get is by examining these trends among children who were born prior to the 2001 Supreme Court mandate and therefore have minimal program exposure. Figure 4 depicts trends in test scores for all the children in our main sample born before the 2001. It shows that early implementers exhibit slightly better test scores than late implementers. This difference in levels is accounted for by state fixed effects, and is natural since early implementers are likely to be states with betterfunctioning governance and institutions. It also shows that older children have better test scores than younger children. This is accounted for by cohort fixed effects. At the same time, for cohorts born before the Supreme Court Mandate, early and late implementers exhibit parallel trends in test scores.

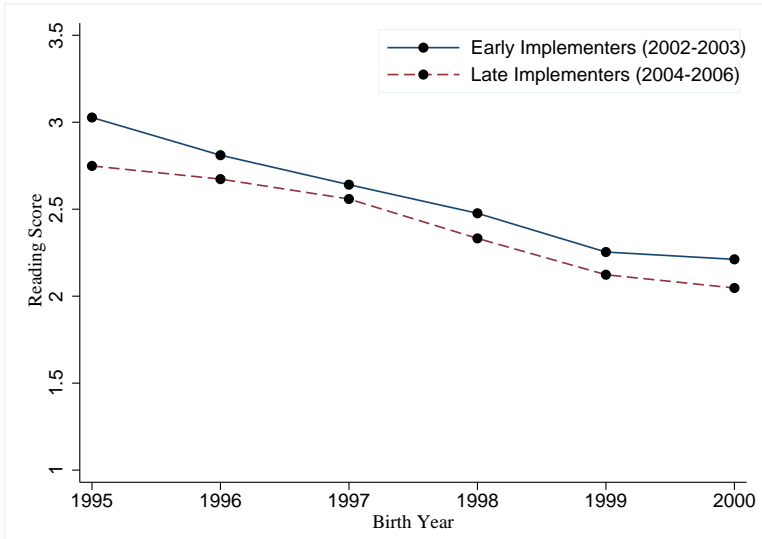

(a) Reading Score

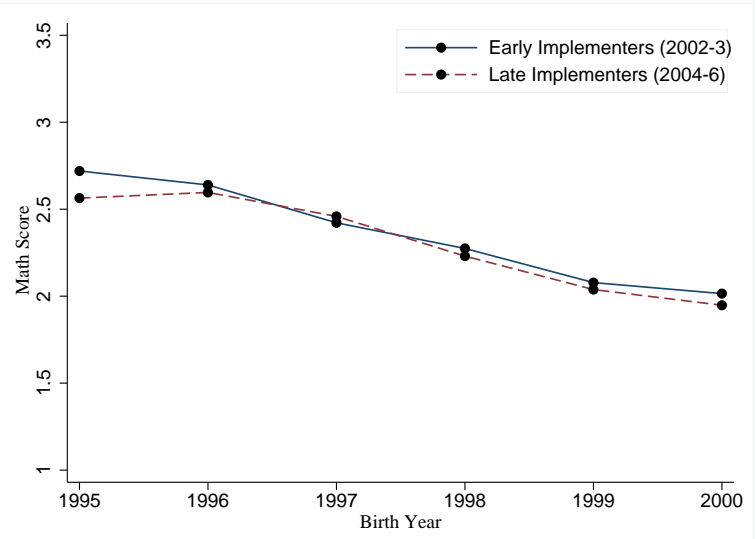

(b) Math Score

Figure 4. Parallel Trends. Notes: This graph depicts the trends in the reading score by early implementers (states implementing the policy in 2002-2003) and late implementers (states implementing the policy in 2004-2006) over the birth cohorts born prior to the 2001 policy mandate.

\section{The Effect of Midday Meals on Test Scores}

In this section, we examine the effect of midday meal exposure on test scores. We begin by describing the correlation between program exposure and test scores. Then we analyze the causal effect of midday meals on test scores through regression analysis, which exploits plausibly exogenous variation in program exposure depending on a child's age, his or her state of birth, and when midday meals were introduced in primary schools in each state. This section presents our main treatment effects. A battery of robustness checks on these baseline results is presented later on in Section 6.

\footnotetext{
${ }^{10}$ ASER does test children up to the age of 16 , but restricting attention to older children, who were at least 12 at the time of program introduction and therefore have no program exposure at all, entails sample loss that precludes analysis by timing of implementation.
} 
4.1. Descriptive Analysis. We start with the simple question of whether, in our raw data, program exposure is associated with increased learning. The answer, furnished in Figure 5 is a clear "yes". It depicts a scatterplot of months of potential program exposure on the $\mathrm{x}$-axis against average test scores on the y-axis, fitted with a linear regression line.

There is a clear positive correlation between exposure and test scores. Children with the lowest level of program exposure (4 months) have scandalously low average reading and math test scores of about 1.07. Concretely, these children just about read a letter and recognize a one-digit number. Columns 1 and 5 of Table 3 present the estimated slope of the regression line depicted in Figure 5. They indicate that from this very low baseline, average test scores increase steadily by about 0.035 points for reading and 0.030 points for math with each additional month of exposure. (This is equivalent to a 0.026 and 0.023 point standard deviation increase, respectively; see Appendix Table A3.) Consequently, average test scores for children with 52 months of exposure (the maximum in our sample) are almost 3 times as high as they are for children with only 4 months of exposure: these children can read a short paragraph and conduct two-digit subtraction with carryover.

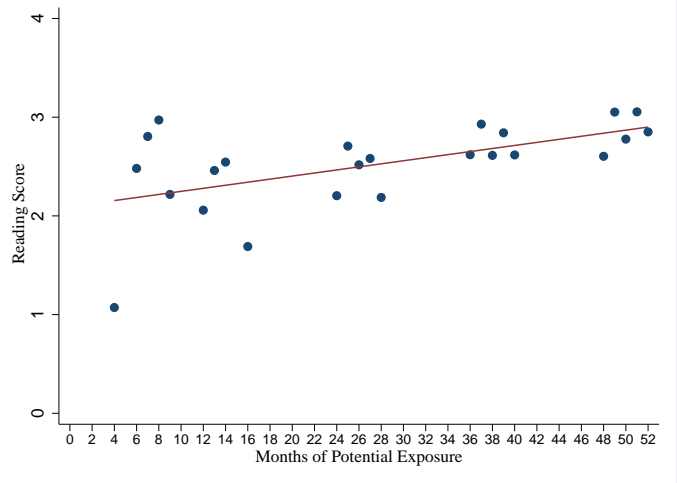

(a) Reading Score

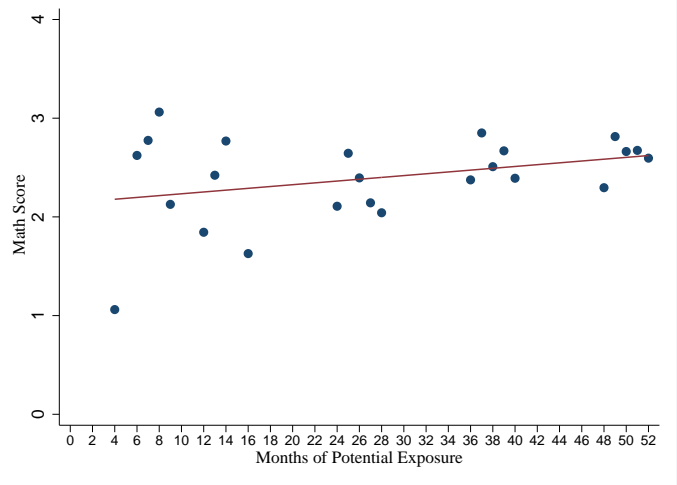

(b) Math Score

Figure 5. Average Test Scores by Months of Potential Exposure. Notes: This scatter plot describes average reading (left panel) and math (right panel) test scores by months of potential exposure.

4.2. Econometric Analysis. The positive relationship between learning and program exposure is striking. But the correlation presented Figure 5 is likely to be an upward bias estimate of the true causal relationship between midday meal exposure and learning, since it captures differences across time, cohorts, or states. More specifically, children surveyed in later years, belonging to older cohorts, and residing in states which implemented the policy earlier are likely to have both longer exposure and higher test scores.

We account for this in columns 2-4 and 6-8 of Table 3, which present OLS estimates for equation (1) for reading and math test scores, respectively. Row 1 presents the treatment effect, $\beta$, which corrects for state, cohort and time fixed effects, as well as state-level time trends. The effect of midday meals on test scores is positive and statistically significant at the $1 \%$ level. In keeping with our priors, this treatment effect is substantially smaller than the simple linear association. The point estimate in columns 2 and 6, which present the baseline treatment effect without controls are roughly one-fourth the size of that in column 1 for reading and one-seventh the size of that in column 5 for math. 
This treatment effect is qualitatively robust to the inclusion of additional controls in columns 3 and 7. Controlling for these variables entails sample loss, and differences in point estimates and the loss of statistical significance for the math score are due entirely to this. (Robustness checks presented in Section 6 using household fixed effects confirm this.) The coefficients of the controls themselves are largely in keeping with our priors. Test scores are lower for girls than they are for boys. Children in larger households perform worse, probably because these households also tend to be poorer. And children whose mother has attended school do considerably better than children whose mothers didn't. These regressions nevertheless demonstrate that the results are qualitatively robust to the inclusion of these controls. The estimates that follow will therefore use the full sample, eschewing these controls.

Columns 4 and 8 allow for a non-linear treatment effect by adding squared months of exposure to the baseline specification. ${ }^{11}$ The estimates in rows 1 and 2 show that the effect of program exposure on test performance is increasing in the first 3 years of exposure and then tapers off in the last 2 years of primary school. We will take this non-linearity into account in future specifications, and use the specification in columns 4 and 8 as our baseline model in robustness checks in Section 6.

To understand the magnitude of these effects, we aggregate exposure in yearly intervals (where 0-1 years is 0-12 months, 1-2 years are 13-24 months, etc.). This has three advantages over the monthly exposure measure. First, it is more natural to think of children in primary school with years as opposed to months of exposure, given that grade promotion occurs annually and primary school extends over the course of 5 years. Second, exposure measured in years rather than months is less "lumpy" (see Figure 3), and this allows us to both avoid out-of-sample predictions for months of exposure for which we have no observations and provides us with enough observations within each year of exposure to estimate confidence intervals for marginal effects. Finally, it facilitates the interpretation of results in the next section, where we explore what may account for the learning effects we estimate in this section.

\footnotetext{
${ }^{11}$ The results for this quadratic specification are broadly consistent with the introduction of higher order polynomials in this regression, as well as semi-parametric estimation. (Results not shown.)
} 


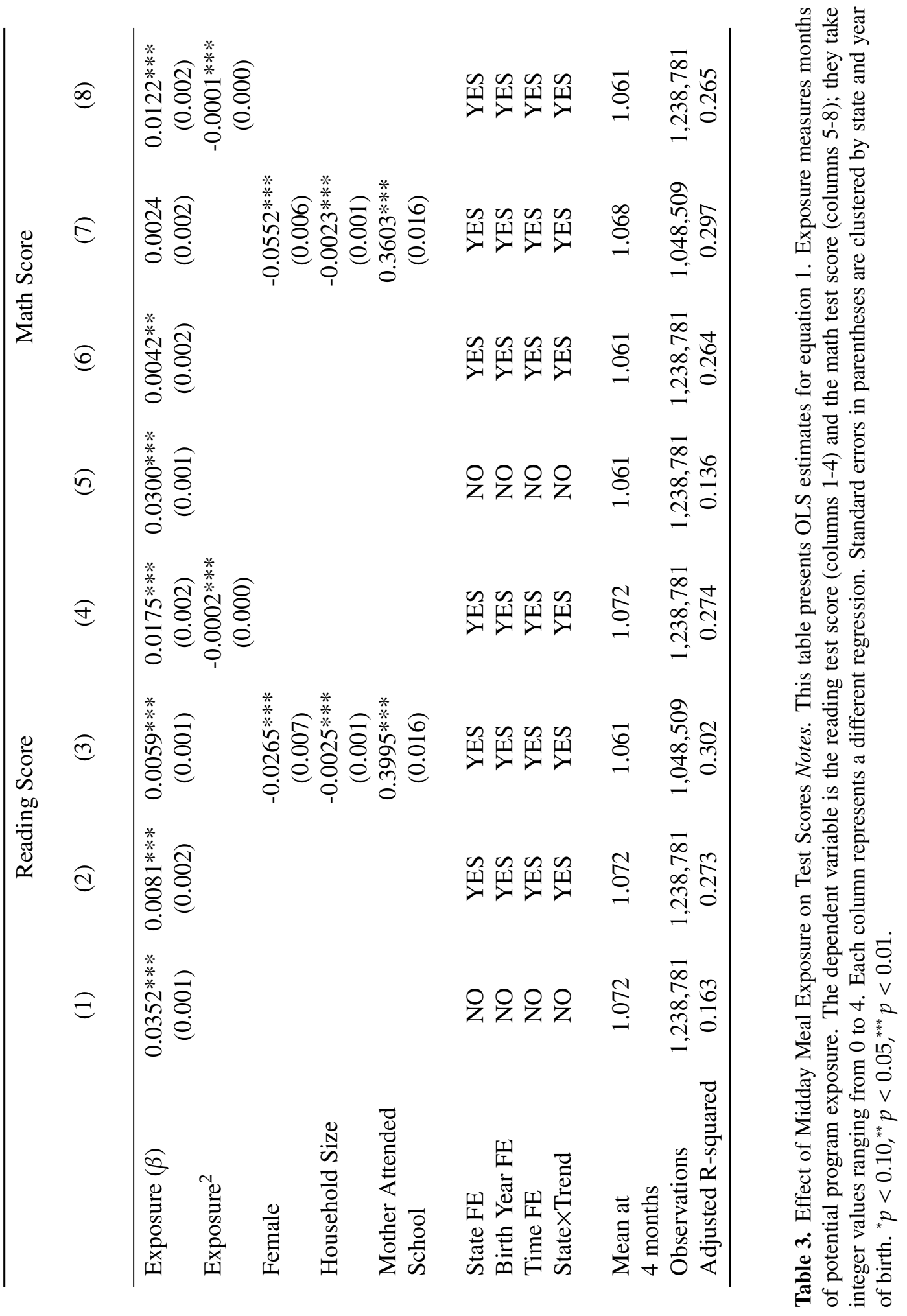


We estimate the following equation with Exposure measured through a vector of 4 dummy variables denoting 1-2, 2-3, 3-4, and 4-5 years of exposure, with 0-1 years of exposure being the exclusion:

$$
y_{i t c s}=\alpha+\beta^{\prime} \text { Exposure }_{i(t c s)}+\delta_{t}+\delta_{c}+\delta_{s}+\gamma_{s} \cdot t+\varepsilon_{i}
$$

where $y_{i t c s}$ is the test score, so the coefficient estimates for the vector of yearly exposure dummies $\beta^{\prime}$ capture the change in test scores as a result of up to one additional year of exposure. The remaining variables are defined as in equation (1).

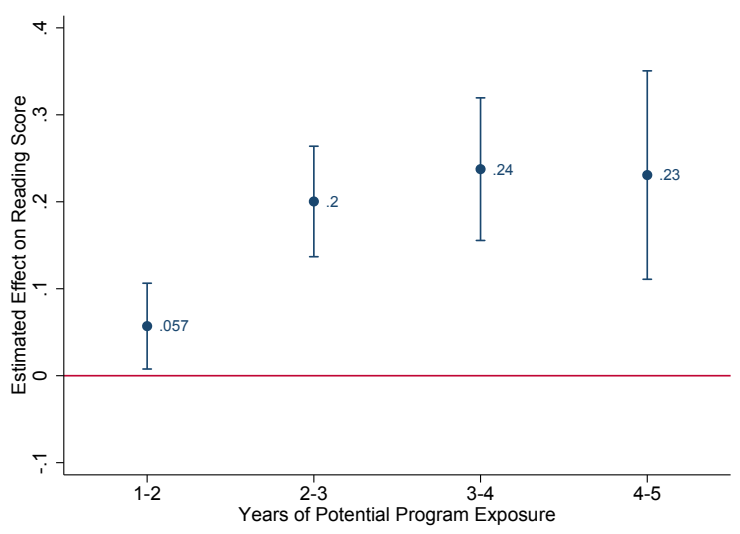

(a) Reading Score

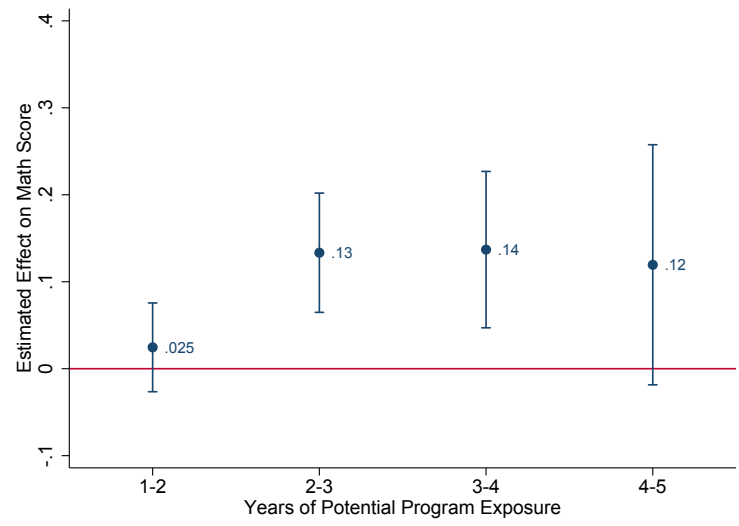

(b) Math Score

Figure 6. Effect of Midday Meal Exposure on Test Scores, by Years of Potential Exposure. Notes: This graph provides a graphical depiction of the OLS estimates for $\beta^{\prime}$ in equation (2). The exclusion is $0-12$ months (i.e. less than 1 year) of potential exposure; 1-2 years correspond to 13-24 months, 2-3 correspond to 25-36 months, and so on. Coefficient estimates for the change in test scores from up to one additional year of exposure are denoted in the graph, and the bars denote the corresponding 95\% confidence intervals, with standard errors clustered by state and year of birth. The full regression results corresponding to this figure are presented in Appendix Table A4.

Figure 6 depicts OLS estimates for $\beta^{\prime}$ in equation (2) graphically; regression results are presented in Appendix Table A4 . The exclusion is $0-1$ years (i.e. 12 months or less) of exposure. It confirms what we saw in the final results of Table 3, namely that learning increases, albeit at a decreasing rate, with exposure to midday meals. Relative to the first year, the second year of exposure increases test scores by a statistically significant 0.057 points for reading, which amounts to an approximately $4.4 \%$ increase relative to the baseline (children with less than 1 year of exposure). For math, the increase in test scores is half this size and statistically insignificant.

Test scores jump dramatically in the third year to a 0.20 point $(15 \%)$ increase in reading and a 0.13 point $(10 \%)$ increase in math, relative to the baseline. This increase in test scores from the second to the third year of exposure is not just economically, but also statistically significant $(\mathrm{p}=0.0$ for both reading and math). The increase jumps slightly to 0.24 (i.e. by $18 \%$ ) for reading and 0.14 (11\%) for math in the fourth year of exposure although the difference relative to three years of exposure is only marginally significant for reading $(\mathrm{p}=0.08)$ and statistically insignificant for math $(\mathrm{p}=0.87)$. 
In the final year of exposure the effect tapers off slightly to 0.23 points for reading and 0.12 points for math. This represents a statistically significant increase relative to the baseline for both subjects (see Appendix Table A4), although the difference is statistically insignificant relative to the previous two years. According to these estimates, a child who has been exposed to midday meals throughout primary school has reading test scores that are $18 \%$ higher and math test scores that are $9 \%$ higher than those of a child with less than one year of exposure. This is equivalent to roughly 0.17 standard deviations for reading and 0.09 standard deviations for math; see Appendix Figure A2.

The fact that relative to the (up to) one year baseline, the increase in test scores is small in magnitude, and in the case of math statistically insignificant, after up to two years of exposure but large and significantly higher thereafter is important in view of the negligible learning effects of school feeding programs documented in the literature to date. In particular, the extant literature has-without exception-examined program effects after at most two years of exposure. What our results indicate is that students may need prolonged exposure in order to reap substantive learning benefits from the program.

\section{AcCounting FOR IMProved Test Scores}

The analysis in the previous section shows that midday meals have a large and statistically significant impact on learning achievement, with test scores for children with exposure throughout primary school, increasing by about $18 \%$ for reading and $9 \%$ for math, relative to those with less than a year of exposure. The literature has stressed two channels through which school feeding programs may improve learning achievement. The first is increased school participation: midday meals may encourage enrollment and attendance, both of which provide children the opportunity to learn in the first place. The second is through improved nutrition: better nourished children have more learning capacity and therefore perform better in school.

Extant quasi-experimental evidence indicates that midday meals improve both school participation and nutritional status of children. Jayaraman and Simroth (2015) report that the introduction of midday meals increased grade 1 enrollment by approximately 25 per cent. Afridi (2010) finds that in Madhya Pradesh, the program provided children with a considerable portion of their daily intake of five nutrients (energy/calories, proteins, carbohydrates, calcium, and iron). We begin this section by examining the enrollment effect of the program in our data, and conducting an accounting exercise, which uses estimates from the previous section and from Jayaraman and Simroth (2015) to put an upper bound on the pure nutrition-learning effect of the program.

Better nourished children are also likely to learn more in schools where other teaching inputs are available. Children need to learn reading and math in class to answer reading and math questions, no matter how well nourished they are. The second part of this section explores this by estimating potential complementarities between program exposure and various schooling inputs.

School lunches are likely to be more effective in improving the performance of more disadvantaged children because they are more likely to enjoy nutritional improvements as a result of the program and are likely to have higher marginal benefits of improved nutrition since they start from a lower baseline nutritional status. We explore this in the third part of this section by examining heterogeneous treatment effects based on two measures of socio-economic status: gender and housing assets. 
Finally, school lunches only improve the nutritional status of children to the extent that families do not fully substitute away food allocations from program recipients to other family members. We investigate this in the last part of this section, which explores whether children living in households that are potentially more likely redistribute resources benefit less from midday meal exposure.

5.1. Enrollment and Nutrition-Learning. A large literature has documented that school feeding programs have a positive effect on school participation; see Adelman et al. (2008), Kristjansson et al. (2007), Bundy et al. (2009), Behrman et al. (2010), Jomaa et al. (2011), Alderman and Bundy (2012) Lawson (2012), and McEwan (2015), for recent reviews of this literature in the context of developing countries. These studies compare school participation with and without a school feeding program. This is not possible in our context because we do not have a pure control group, which has never received midday meals: all the children in our sample have at least 4 months of exposure. In other words, there may well be children who would not have been in school without a midday meal, but decide to enroll because a midday meal is provided. However, we cannot identify this effect.

In the absence of a pure counterfactual, the best we can do with our data is examine the effect on enrollment of increased program exposure. ${ }^{12}$ We are unlikely to see large effects here for the simple reason that baseline enrollment over our period of observation is high to begin with. Self-reported net enrollment in our data is, on average, roughly 97\% (See Table 2). This is in line with official figures. For example, a recent survey commissioned by the ministry of Ministry of Human Resource Development to assess the number of out of school children found that in 2014, only 3\% of 6-10 year-olds in rural areas were out of school (Educational Consultants India, 2014). In view of this, it is unsurprising that we find modest effect sizes on school participation. An additional year of exposure increases enrollment in our data by a statistically insignificant and meager 0.3 percentage points between 2-4 years of exposure; see Appendix Table A5.

Baseline enrollment is, in fact, unlikely to be as high as $97 \%$ in the absence of this program. Jayaraman and Simroth (2015), for example, find that the introduction of midday meals increased school enrollment by 13 percent as a whole. This was driven by a 25 per cent increase in enrollment in grade 1, with no statistically significant increased in enrollment in grades $2-5$. The enrollment effects described in the previous paragraph provide some corroborative evidence for the latter finding, but do not really capture the former. Beyond this, there is not much more that can be said about enrollment effects of the program from these data.

Newly enrolled children can, of course, do better in tests both because they are now in school, and because they are better nourished. In order to understand to what extent nutrition alone can account for the impressive learning effects documented in the previous section it makes sense to look at children who would be in school regardless of program exposure, since any increase in test scores that comes from them presumably does so through improved nutrition-the nutrition-learning channel. Consider the following accounting exercise. Let $\Delta S$ denote the average change in test scores resulting from midday meal exposure throughout primary school (i.e. for the full 52 months in our sample).

\footnotetext{
${ }^{12}$ The introduction of midday meals is likely to also raise attendance. This may lead to higher learning simply because children are now coming to school. While we do not have attendance information in our data to directly examine the increase in attendance in response to the program, note that it is unlikely to drive the learning effects that we find. The reason is that identification comes from longer duration of program exposure compared to at least 4 months of exposure. Whereas attendance might go up when meals are introduced for the first time, it are unlikely to increase any further with additional years of exposure once the program is in place.
} 
Let $n_{a}$ denote the proportion of always-takers-those children who would be in school regardless of the midday meal program. Let $n_{e}$ denote the proportion of new enrollments-children who join school because of the midday meal but would not be in school otherwise. Finally, let $n_{o}$ denote the proportion of children who remain out of school no matter what. Notice that $n_{a}+n_{e}+n_{o}=1$. The average treatment effect can be disaggregated as follows:

$$
\Delta S=n_{a} \Delta S_{a}+n_{e} \Delta S_{e}+n_{o} \Delta S_{o}
$$

where $\Delta S_{a}$ is the change in test scores of the always takers; $\Delta S_{e}$ is the change in test scores for children who are newly enrolled in response to the program; and $\Delta S_{o}$ is the change in test scores for out of school children. Cetirus paribus, $\Delta S_{a}$ captures the nutrition-learning channel: this is the increase in test scores for children who would be enrolled in school even in the absence of the midday meal scheme, so assuming nothing else changes (e.g. no externalities on account of increased enrollment) any improvement in learning that they enjoy must come from their improved nutritional intake. $\Delta S_{e}$, by contrast, captures both nutrition and enrollment effects: these are children who are newly enrolled in school and also enjoy better nutrition as a result. With so many degrees of freedom, the best we can do in the context of our data is to place bounds on this nutrition-learning channel, $\Delta S_{a}$, by placing additional parameter restrictions on equation (3).

To do this, first assume that $\Delta S_{o}=0$, that is children who do not enjoy a midday meal because they are not in school do not experience any change in their test scores. Second, from Table 2 we see that enrollment has remained stubbornly at around $97 \%$ across the survey years, so it seems fair to assume that the proportion of children who remain out-of-school is $n_{o}=0.03$. This means that $n_{a}=0.97-n_{e}$. Third, assume that $S_{e} \geq 0$, that is newly enrolled children do not perform worse on tests than they would otherwise do. With these restrictions, we can rearrange equation (3):

$$
\Delta S_{a}=\frac{\Delta S-n_{e} \Delta S_{e}}{0.97-n_{e}}
$$

Jayaraman and Simroth (2015), find that class 1 increased by roughly $25 \%$ at the outset of the midday meal scheme, when baseline enrollment was only 85 percent. Given that we do not have pure counterfactual, consider this a plausible upper bound for the enrollment effect of the midday meal scheme. Set $n_{e}=0.25, \Delta S_{e}=0$, and use the estimates from the previous section of $\Delta S=0.23$ for reading and $\Delta S=0.12$ for math after 4-5 years of exposure (see Figure 6). This allows us to place a plausible upper bound on the nutrition-learning effect of $0.32(0.23 \mathrm{SD})$ for reading and 0.17 $(0.13 \mathrm{SD})$ for math. Under the assumptions spelled out above, this is effectively what the increase in reading and math scores would be if cognitive skills of newly enrolled children were unchanged, and the improvement in test scores came entirely from a nutrition-learning channel from children who would be enrolled in school whether or not they received a school lunch.

5.2. Complementarity. It is unlikely that school lunches work in isolation. For instance, if teachers are frequently absent from school then the program may encourage children to go to school and may improve their nutritional status, but they are unlikely to learn much once they are there. In general, it seems plausible that schooling inputs that directly foster learning-such as teachers, books, or 
blackboards - serve to translate higher enrollment and nutritional status arising from school feeding programs into improved cognitive skills.

From 2009-2012 ASER surveyed a public school in each village where they conducted household surveys. ${ }^{13}$ This allows us to explore potential complementarities between schooling inputs and midday meal exposure. Hence, in the remainder of this subsection we restrict the sample to 2009-2012 and match the school survey to the household survey data for these years at the village level. Fewer survey years and missing information on schooling inputs, has the drawback that we are only able to match roughly $40 \%$ of the children in our main sample, that too only for later years. ${ }^{14}$

Using this matched sample we show, in Section 6, that the results of our main specification with quadratic months of exposure are robust to the inclusion of a wide array of schooling inputs. Here, for ease of interpretation, we measure exposure linearly in terms of years rather than quadratically for months, and investigate the presence of potential complementarities between schooling inputs and midday meals by estimating the following model:

(4) $y_{i t c v s}=\alpha+\beta$ Exposure $_{i(t c s)}+\phi$ Input $_{v t s}+\theta\left(\right.$ Exposure $_{i(t c s)} \times$ Input $\left._{v t s}\right)+\delta_{t}+\delta_{c}+\delta_{s}+\gamma_{s} \cdot t+\varepsilon_{i t c v s}$

where Exposure $=1,2, \ldots 5$ measures the linear years of potential program exposure and Input denotes a schooling input in village $v$ for the government school surveyed in that village. The remaining variables are defined as in equation (1). Our parameter of interest is $\theta$, which captures potential complementarities between program exposure and schooling inputs. If better nourished children benefit more from these inputs in the learning process, we would expect $\theta$ to be positive.

We examine complementarities between program exposure and six separate schooling inputs. Teacher attendance refers the number of teachers present in school on the day the ASER school survey took place, as a fraction of the total number of appointed teachers. Usable Blackboard is a dummy variable reflecting the presence of at least one usable blackboard in either grade 2 or grade 4 . Learning Material indicates the availability (or not) of supplementary learning materials, such as books, in the school. Separate Classroom is a dummy indicating whether grade 2 and grade 4 are taught along with other grades or not. Tap in School indicates whether or not the school has a functional drinking water tap. No. Classrooms indicates the total number of usable classrooms in the school.

\footnotetext{
${ }^{13}$ While ASER started the school surveys in 2007 , the first round has very comparability to subsequent rounds, which provide a much more comprehensive list of schooling variables.

${ }^{14}$ ASER reports a long list of schooling variables from which we choose a subset. Our choice of variables is driven both by the fact that they have the fewest missing observations, and also because they are relevant learning inputs.
} 

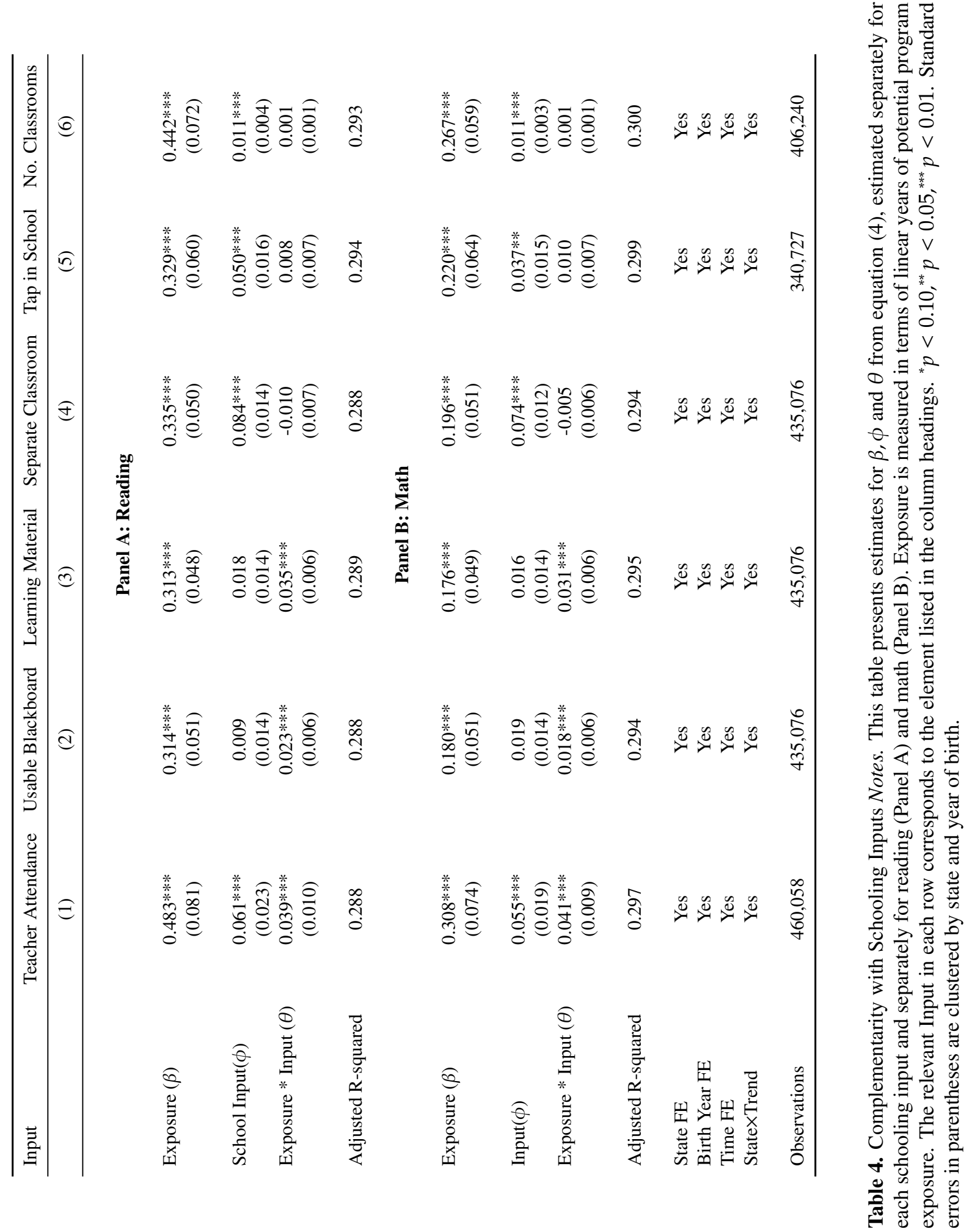
The findings are reported in Table 4, which presents estimates for $\beta, \phi$ and $\theta$ from equation (4), estimated separately for each schooling input, separately for reading (Panel A) and math (Panel B). The results indicate the presence of significant complementarities with respect to those teaching inputs that are directly related to learning opportunities of children. For instance in column 1, we see that a 10 percentage point increase in teacher attendance is associated with a $0.006(0.005)$ point increase in reading (math) scores on its own. However, when combined with one additional year of exposure to school lunches, a 10 percentage point increase in teacher attendance is associated with a roughly 0.01 point increase in reading and math scores. Similarly, access to a functional blackboard (column 2) or supplementary learning material (column 3) don't by themselves improve test scores. However, when combined with midday meals they improve both reading and math test performance. By contrast, in columns 4-6 we see that more general schooling infrastructure like the total number of classrooms, access to drinking water tap or availability of separate classrooms for each grade are not complementary to midday meals. Together these results suggest that schooling inputs that are used in classroom instruction are complements to midday meals, but more general schooling infrastructure is not.

5.3. Heterogeneous Treatment Effects. The efficacy of school feeding programs in improving learning achievement depends on whether they improve nutrition and whether this translates into better school performance. There are two corresponding reasons why disadvantaged children may derive greater benefit from the program than more privileged children. First, as Afridi (2010) has documented, midday meals are more likely to increase the nutritional intake of disadvantaged children. Second, since poorer children start from a lower nutritional baseline, the marginal benefits of improved nutrition are likely to be larger for them than for more privileged children who tend to have better nutritional status; see Strauss and Thomas (1998) and Strauss (1986) who document an increasing concave relationship between nutrition and productivity.

Figure 7 investigates the presence of heterogeneous treatment effects along two dimensions: gender and housing assets. Female disadvantage in terms of educational outcomes has been well-documented for India (see for example, Kingdon $(2002,2007)$ ). Following the logic outlined above, we would expect that baseline test performance would be lower for girls than for boys, but that girls would be more responsive to program exposure than boys. The focus of the ASER survey is on testing children, and as a consequence information on economic status is rudimentary to say the least. Still, enumerators do record some proxies for wealth for the years 2008-2012, the most complete of which is housing assets. ${ }^{15}$ This comprises a record of the material from which a house is made, where "Pucca" denotes a house made of durable materials such as brick, stones or cement, "Kutcha" denotes a house made of less durable materials such as mud, reeds, or bamboo, and "Semipucca" denotes something in between. Hence, Pucca (Kutcha) is a proxy for relatively high (low) economic status. Here again, we expect that children living in Pucca houses have better baseline performance than children living in poorer quality housing, but that the increase in test scores with exposure is larger for the latter, more disadvantaged, group relative to the wealthier former group.

Figure 7 shows that our first prior is confirmed: girls perform worse than boys, as do poorer children (those living in Semipucca or Katcha housing) relative to wealthier children. However, there is no

\footnotetext{
${ }^{15}$ Patterns are similar for other measures of economic status, such as a broader asset index constructed using principal components analysis. However, reduced sample sizes due to missing observations on these indicators preclude the calculation of confidence intervals for marginal effects.
} 


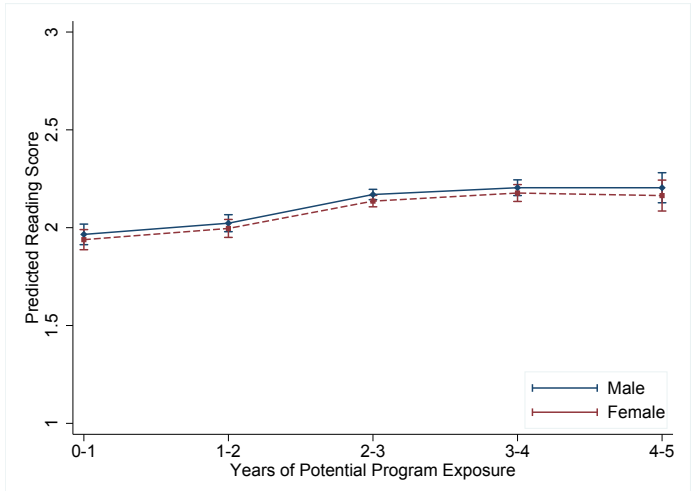

(a) Gender

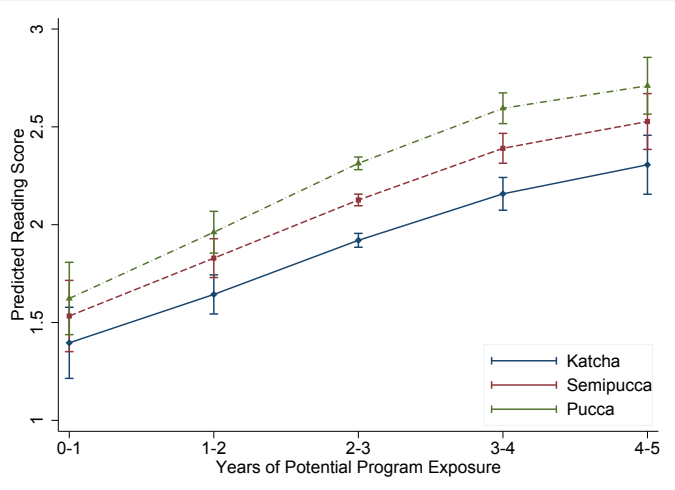

(b) Housing

Figure 7. Heterogeneous Responses. Notes: The graph above depicts predicted reading test scores for different years of potential exposure by gender (panel a) and housing assets (panel b). Bars denote $95 \%$ confidence intervals, with standard errors clustered by state and time.

evidence that disadvantaged children enjoy higher marginal benefits from program exposure. The disadvantage gap remains virtually unchanged; the graphs indicate neither convergence on divergence of performance across groups with program exposure. This "negative" result is likely to be a reflection of two facts. First, these are crude measures of disadvantage compared to measures like consumption expenditure or (better yet) baseline caloric intake; this may mask differences in marginal effects of program exposure. Second, these children are starting from a very low baseline in terms of nutritional status. Deaton and Drèze (2009) report that three quarters of the Indian population lives in households whose per capita calorie consumption lies below "minimum requirements" and that even privileged Indian children are mildly stunted. It is possible, in this context, that marginal effects of nutritional input are high, and roughly comparable, for both relatively privileged and relatively disadvantaged children.

5.4. Intra-Household Redistribution. Our implicit assumption throughout this paper has been that exposure to midday meals improves the nutritional status of children. But this is not self-evident. Although midday meals are targeted (in-kind) transfers, the program may nevertheless lead to the redistribution of resources away from a primary school-aged child towards other family members. (See, for example, Das et al. (2013) for recent evidence regarding schooling inputs and intra-household substitution.) In the extreme case the transfer may be neutralized, in that families who formerly provided this food to their child may, with the introduction of midday meals, substitute resources away from that child altogether, towards other family members. This seems unlikely, but it is fair to say that intrahousehold redistribution may temper the effect of the midday meal program on learning outcomes. The extent to which this takes place depends, among other things, on parental preferences and family composition. Redistribution may be triggered by additional children in the household, traditional son-preference, or simply by additional mouths to feed.

Table 5 investigates these possibilities by examining whether midday meal exposure has a differential impact on learning, separately, for children who (1) live in larger households, (2) have at least 1 
sibling, (3) have at least one sibling who is not eligible for the midday meal program or (4) are female and have a male sibling.

The positive coefficients in the first row of Table 5 confirms our baseline results that each additional year of exposure to the program improves test scores significantly. The negative coefficient on the interaction term in columns 1 and 5 suggests that children living in larger households experience smaller improvements in reading scores for additional years of exposure to the program compared to children living in smaller households. Nevertheless, the marginal effect of one additional member in the household is close to zero, suggesting negligible redistribution away from children in larger households. It could however be the case that when redistribution occurs, it takes place across children and not from children to adults. We explore this possibility in columns 2 and 6 by comparing children with and without any siblings. The findings once again suggest that the additional resources from the free school lunch sticks to the recipient child and we do not find any evidence of redistribution to other children in the household.

The implicit assumption in columns 2 and 6 is that households do not distinguish between additional children based on their eligibility for midday meals in school. However, the need for redistribution across children is likely to arise only when the household budget constraint binds. Additional siblings lead to lower resources per child in the household only when they are not eligible for midday meals. On the other hand, siblings eligible for free meals in school are likely to relax household budget constraint. Hence, in columns 3 and 7, we compare children with equal number of siblings but varying in the sibling's eligibility for midday meals in school. We categorize siblings as non-eligible for school lunches either if they are too young to be in school or if they have already completed primary school. The coefficients imply that children who have siblings receiving midday meal in school experience a $0.08(0.05)$ point increase in reading (math) scores for each additional year of policy exposure. However, for a child with siblings who are not receiving free meals in school, the reading or math score goes up only by half that amount. This suggests the presence of partial intrahousehold redistribution away from the child receiving midday meal in school to the child not eligible for midday meal in school.

Finally, we investigate intra-household redistribution against the backdrop of a well-known male bias in Indian households. Columns 4 and 8 compare the effect of program exposure on female children with and without male siblings. Our prior here is that in the presence of an inherent male bias, parents are more likely to spend the additional resources freed up on the male sibling. However, the coefficient estimate, although negative, is statistically significant only in the case of reading, pointing once again to negligible redistribution.

Overall we find modest levels of substitution within the household. Moreover, the results suggest that the extent of redistribution depends on whether or not the household budget constraint binds. 
SCHOOL FEEDING AND LEARNING ACHIEVEMENT: EVIDENCE FROM INDIA'S MIDDAY MEAL PROGRAM 27

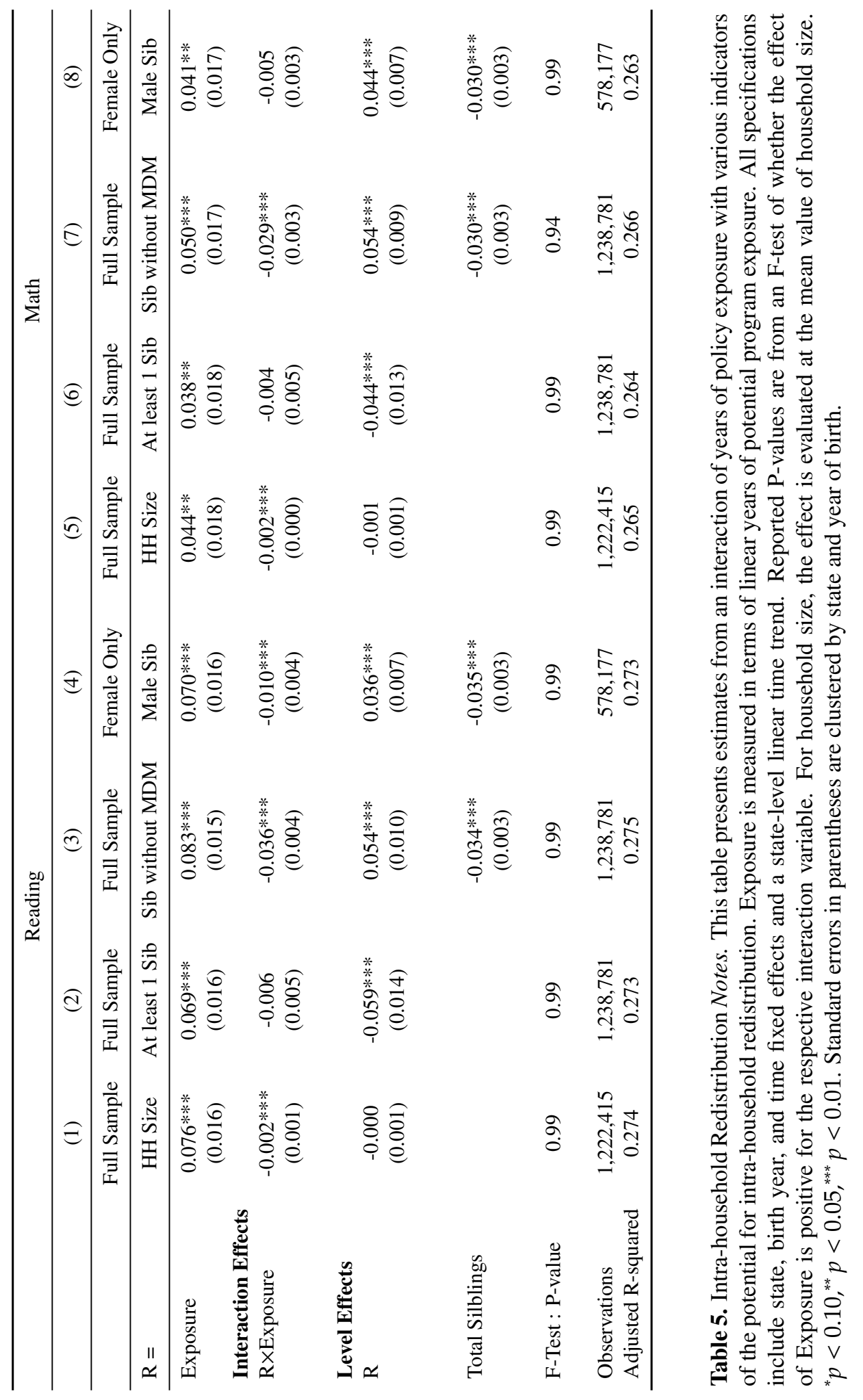




\section{Robustness Checks}

In this section, we run a number of robustness checks on our main result from Section 4. Our chosen specification corresponds to that in columns 4 and 8 of Table 3, with a quadratic exposure in months, although the findings in this section hold for the linear specification as well. More specifically, in what follows, we report estimates for $\beta_{1}$ and $\beta_{2}$ for variants of the following equation, where Exposure is measured in terms of months:

$$
y_{i t c s}=\alpha+\beta_{1} \cdot \text { Exposure }_{i(t c s)}+\beta_{2} \cdot \text { Exposure }_{i(t c s)}^{2}+\delta_{t}+\delta_{c}+\delta_{s}+\gamma_{s} t+\varepsilon_{i}
$$

Our robustness checks address six main concerns and show that our findings are robust to them. First, we investigate whether our results are robust to the inclusion of potentially confounding changes in other schooling inputs. Second, there was a change in how math test performance was evaluated between the first two survey years and the subsequent 6 years. We deal with this by considering two alternative standardizations of test scores, as well as by dropping the first two years of observation, which were subject to a different assessment scale.

We have thus far restricted our attention to children of official primary school age since these 6-10 year olds were the intended target of the Supreme Court mandate. The drawback of this age restriction is that we did not have a pure control group with no exposure at all, or a full exposure group with the 5 complete years of program exposure. The third robustness check investigates what happens when we include the full potential range of exposure by extending the sample to 5-11 year olds.

The main analysis employs an ITT framework, in which identification comes from variation in program exposure across states, time, and the child's age at program exposure. Our econometric specification accounts for systematic variation in test performance by state, cohort and time, as well as linear state-level time trends. However, a fourth nagging concern is the potential for unobserved heterogeneity at the local or even the family level that may be correlated with both test performance and program exposure. We deal with this by estimating household fixed effects.

Fifth, although we include state fixed effects and state-level linear time trends, we may still be concerned that the timing of implementation may be correlated with (potentially non-linear) trends in learning. We deal with this by examining to what extent timing drives our results by considering alternative samples of states based on the timing of implementation.

A final concern is estimation. All of our regressions thus far have been estimated using OLS. The simple rational for this choice of estimator was ease of interpretation. Strictly speaking, though, we should be using an ordered response model since test scores are an ordinal dependent variable. We address this by estimating ordered logit and probit models.

6.1. Schooling Inputs. Our main econometric specification accounts for systematic variation in test performance by state, cohort and time, as well as linear state-level time trends. However, one concern with quasi-experimental studies of this nature is the possibility of simultaneous changes. Jayaraman and Simroth (2015) find no contemporaneous change in schooling inputs with the introduction of midday meals. Still, in this section we control for a range of schooling inputs that could be spuriously 
correlated with midday meal exposure. As explained in Section 5.2, this entails a considerable loss in sample size since comprehensive school surveys were only conducted from 2009-2012.

The results are reported in Table 6. Column 1 reports the average effect of an additional month of exposure for the reduced sample of children, after accounting for state, birth year, and time fixed effects and a state-level linear time trend. The point estimate indicates a statistically significant 0.05 (0.04) point increase in reading (math) scores for an additional month of exposure which is tempered with each additional month of exposure (negative coefficient on the quadratic term). The corresponding increase in the full sample is 0.02 (0.01) for reading (math) (see Section 4.2). This difference in point estimates is driven by the fact that the effective control group, with fewer years of exposure, now has less or no representation of older cohorts who are towards the fag end of their primary school. The average child in the 2009-2012 sample was less than 2 years old when midday meal was instituted in her state. On the other hand, the average child is close to 4 years of age when midday meal started in her state in the full sample. A full distribution of age at the start of the program is provided in Appendix Table A2. It shows that the reduced sample has only 2\% children in the 6-10 age group compared to more than $25 \%$ in the full sample. Consequently, the group with fewer years of exposure in the 2009-2012 sample has lower average test score driven by the lower age composition. Due to the selectivity we should exercise caution while interpreting the magnitude of these effects. Nevertheless, the estimates are insightful when compared across columns with various control for schooling inputs.

Column 2 and 6 control for teacher attendance. As can be expected, teacher attendance is positively associated with test scores. Most importantly, the inclusion of teacher attendance does not affect the coefficient on policy exposure significantly. Columns 3 and 7 account for the availability of usable blackboards and whether different grades are taught in different classrooms. Once again, the inputs themselves have a positive impact on test scores but hardly affect the coefficient on the policy exposure. Finally columns 4 and 8 control for the availability of supplementary learning material in school, total number of usable classrooms and access to a functional tap for drinking water. Overall, the effect of midday meals remains robust to the inclusion of various controls. 


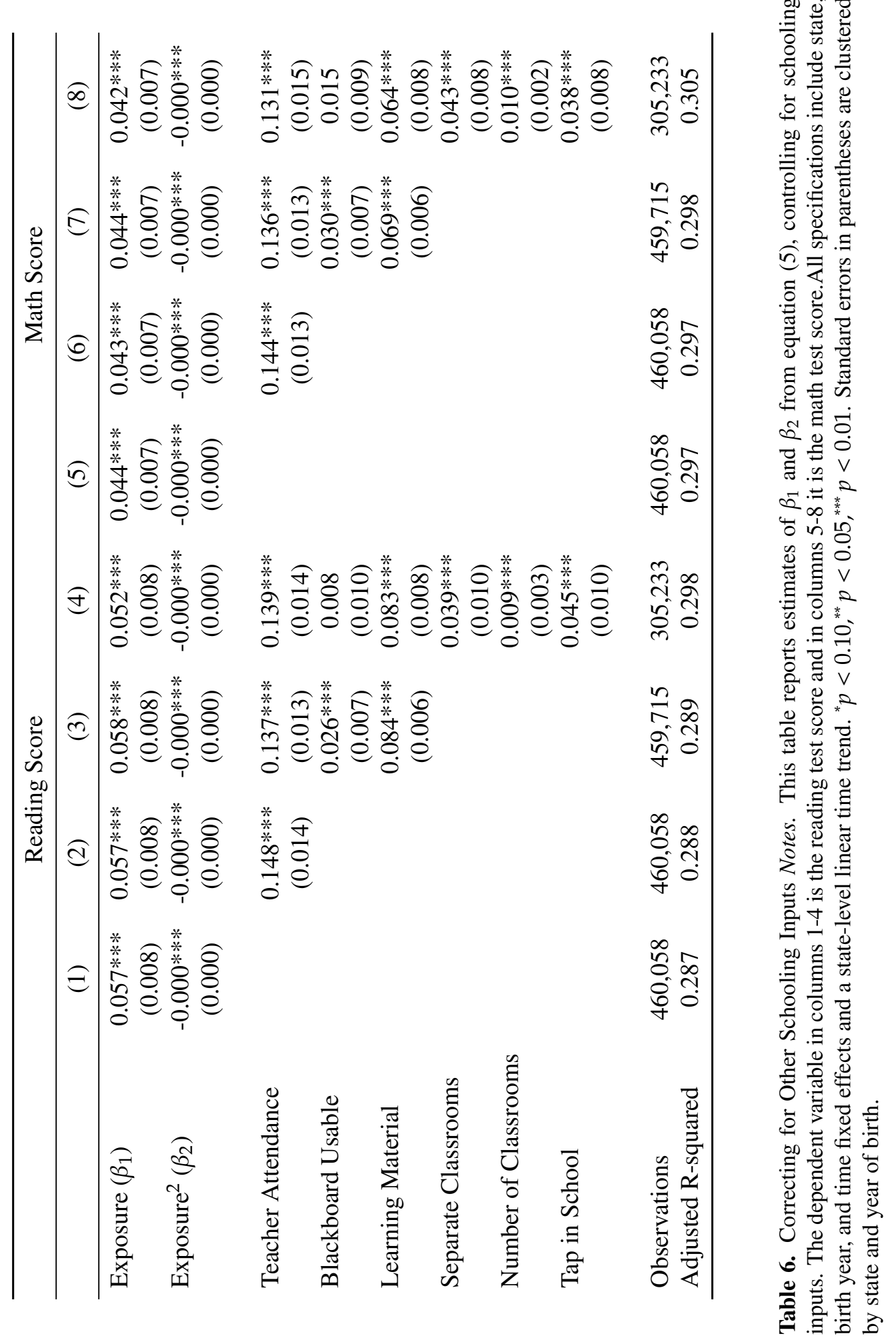


6.2. Test Score Measurement. As mentioned in Section 3.1, ASER's math tests comprise 4 levels of mastery: single-digit number recognition, double-digit number recognition, two-digit subtraction with carry over, and three digit by one digit division. For both tests separately, the child is marked at the highest level he or she can do comfortably. From 2007-2012, scores took 5 integer values: 0, 1, 2, 3 and 4. In 2005 and 2006, however, ASER aggregated single and double digit number recognition, so math test scores took on only 4 values. In the analysis up to now, we have coded single or double digit mastery in 2005 and 2006 as a math test score equal to 2, so our data contain no math test score values equal to 1 in those two years. This means that average test scores are mechanically higher in the first two survey years than in later survey years. Survey year fixed effects will pick up part of this, but since children surveyed in early years are likely to have lower exposure, this measurement error may lead to upward bias in the estimated effect of exposure for low levels of exposure.

We address this measurement error by standardizing the math test score in two ways: first, through z-scores, and second by constructing Angrist-Levy Indices following Angrist and Lavy (1997). The z-scores are constructed in the usual manner, by standardizing the test score separately for each survey year. The Angrist-Lavy measure takes this standardized test score and assigns the index a value 0 if the standardized score is 0 , a value 1 if it is less than equal to one-half, and a value 2 if it is greater than one-half. In addition, we drop survey years 2005 and 2006, which employed a different scoring system than the remaining years. 


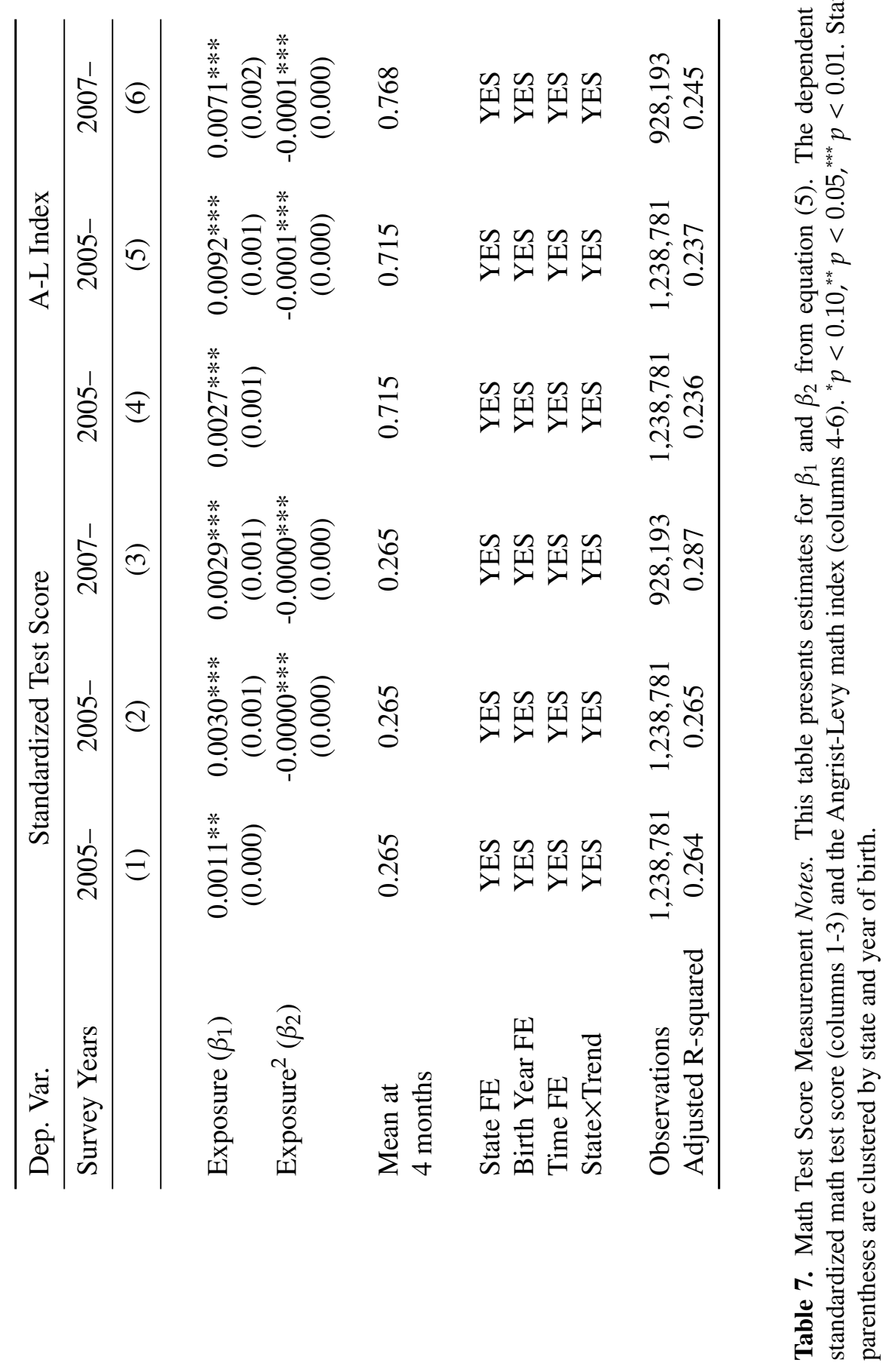


Table 7 reports regression estimates analogous to those in Table 3, except that instead of raw math scores, the dependent variables in Columns 1-3 are standardized math test scores and in Columns 4-6, they are the Angrist-Levy index for math. Columns 1-2 and 4-5 include the full 8 years of observation while Columns 3 and 6 include only those survey years where test scores were comparable, ranging over $0-4$. The results in Table 7 are qualitatively identical to those in Table 3, with children who have higher exposure displaying significant improvements in test scores, albeit at a decreasing rate. This indicates that the change in the math assessment scoring has no bearing on our main result.

6.3. Extended Age Sample. Our main analysis restricts attention to the sample of children of primaryschool age, namely 6-10 year olds. The rationale for this sample restriction was twofold. First, the Supreme Court mandate pertained to primary schools, which cover precisely this age group. Second, some localities offer feeding programs to younger children, in "Angawadis" that care for preschool children, or older children in secondary schools. While there is no systematic pattern across states in these offerings, including younger and older children in the sample would run the risk of "misallocation" of children to the control group when, in fact, they received a school feeding program. However, as we saw in the main analysis, the drawback of the sample restriction to 6-10 year olds is that we had neither a pure control group with 0 months of exposure, nor did we have children who had received the full 5 years of exposure. In this section, therefore, we extend our sample to the 5-11 year age group. Since 5 year olds are not yet in primary school, and 11 year olds have potentially finished primary school, our maintained assumption here-despite the caveats raised above- is that the former have 0 years and the latter, the full 5 years of exposure.

Table 8 reports regression estimates analogous to those in Table 3 for this extended sample. The results are qualitatively identical in terms of sign and statistical significance, and the point estimates indicate, if anything, larger treatment effects for each of the specifications in both reading and math. 


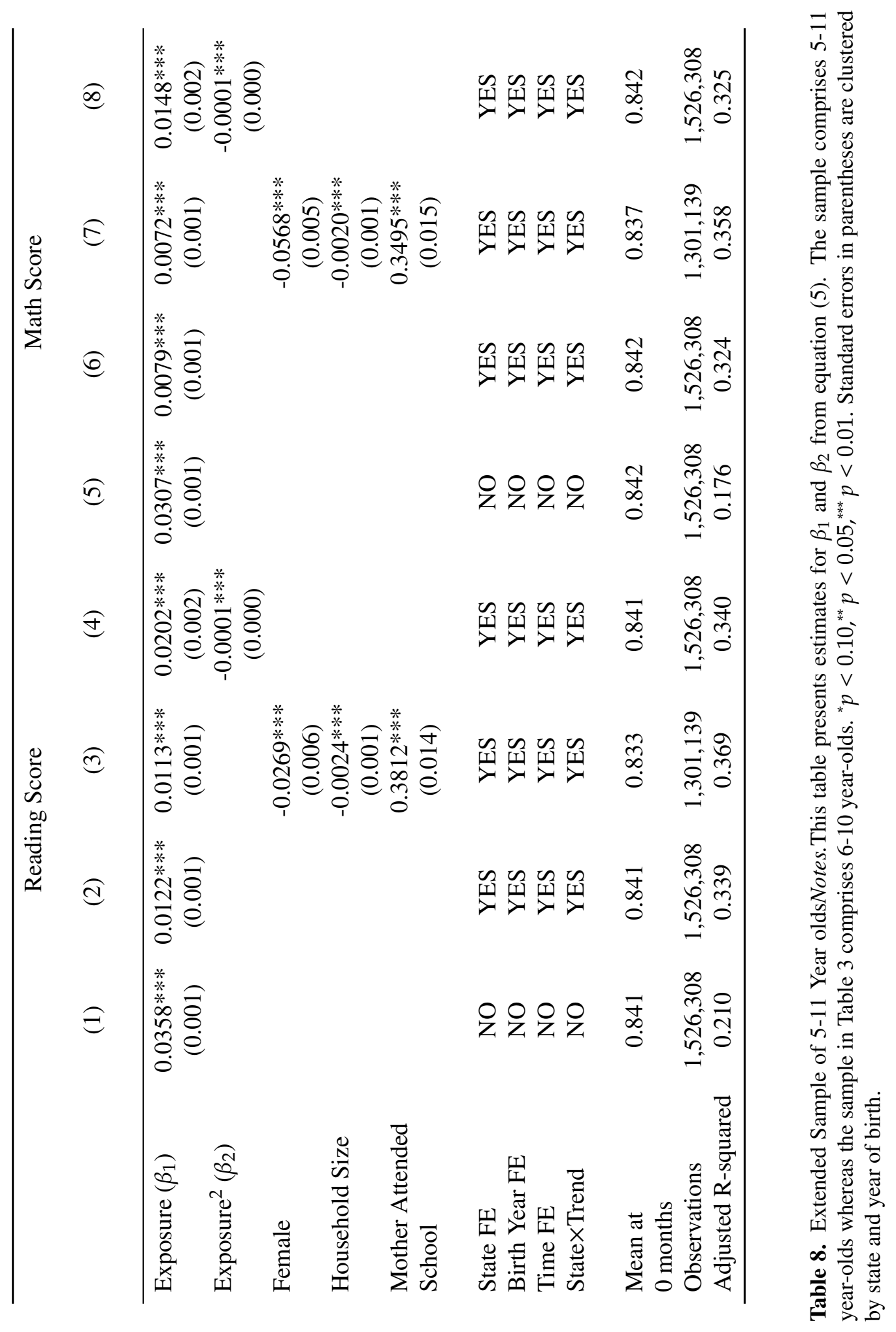


6.4. Household Fixed Effects. The main results exploit variation in exposure based on a child's state of residence, when that state instituted midday meals, and whether the child was of primary school age. This neglects the possibility that there may be unobserved heterogeneity at the family level. More specifically, it is plausible that children from better-off families have higher test scores, and already provided their children with lunches, resulting in downward bias in the treatment effect of exposure. We account for this by estimating household fixed effects, which exploits variation in exposure across different children in the same family. Table 9 presents the results; columns $1 \& 2$ and $3 \& 4$ are analogs of columns $2 \& 4$ and $6 \& 8$ in Table 3 respectively, with household fixed effects. They suggest that, indeed, the estimates in Table 3 may be downward biased estimates of the true treatment effect. The treatment effects estimated with household fixed effects are about twice as large, with each additional month of exposure leading to about a 0.03-0.04 point increase in test scores.

\begin{tabular}{lcccc}
\hline \multicolumn{1}{c}{ Reading Score } & \multicolumn{4}{c}{ Math Score } \\
& $(1)$ & $(2)$ & $(3)$ & $(4)$ \\
\hline Exposure $\left(\beta_{1}\right)$ & $0.0335^{* * * *}$ & $0.0415^{* * *}$ & $0.0258^{* * * *}$ & $0.0319^{* * *}$ \\
& $(0.001)$ & $(0.003)$ & $(0.001)$ & $(0.003)$ \\
Exposure $^{2}\left(\beta_{2}\right)$ & & $-0.0001^{* * *}$ & & $-0.0001^{* * *}$ \\
& & $(0.000)$ & & $(0.000)$ \\
& & & & \\
Household FE & YES & YES & YES & YES \\
Birth Year FE & YES & YES & YES & YES \\
State $\times$ Trend & YES & YES & YES & YES \\
& & & & \\
Baseline Score & 1.305 & 1.305 & 1.266 & 1.266 \\
& & & & \\
Observations & $1,238,781$ & $1,238,781$ & $1,238,781$ & $1,238,781$ \\
Adjusted R-squared & 0.337 & 0.338 & 0.318 & 0.319 \\
\hline
\end{tabular}

Table 9. Household Fixed Effects Notes. This table presents estimates for $\beta_{1}$ and $\beta_{2}$ from equation (5) with household fixed effects. ${ }^{*} p<0.10,{ }^{* *} p<0.05,{ }^{* * *} p<0.01$. Standard errors in parentheses are clustered by state and year of birth.

6.5. Ordinal Dependent Variable. We have so far relied entirely on OLS estimates, which can be readily interpreted. The problem with this approach is that the dependent variable in our regressions is an ordinal response variable, and estimating it using OLS results in nonconforming predicted probabilities and heteroskedasticity. We deal with this by estimating our main results using two alternative estimation methods: ordered logit and ordered probit. The results, presented in Table 10 show that the results are, once again, qualitatively identical to our main results.

6.6. Timing. Table 11 explores to what extent the timing of implementation influences our result by considering alternative samples based on the date of program implementation. It includes state, birth year and time fixed effects, as well as state-specific time trends. Column 1 excludes pilot districts, 


\begin{tabular}{lcccc}
\hline & \multicolumn{2}{c}{ Ordered Logit } & \multicolumn{2}{c}{ Ordered Probit } \\
& Reading & Math & Reading & Math \\
& $(1)$ & $(2)$ & $(3)$ & $(4)$ \\
\hline & & & & \\
Exposure $\left(\beta_{1}\right)$ & $0.020^{* * *}$ & $0.012 * * *$ & $0.014 * * *$ & $0.010^{* * * *}$ \\
& $(0.004)$ & $(0.004)$ & $(0.002)$ & $(0.002)$ \\
Exposure $^{2}\left(\beta_{2}\right)$ & $-0.000^{* * *}$ & $-0.000^{* * *}$ & $-0.000^{* * *}$ & $-0.000^{* * *}$ \\
& $(0.000)$ & $(0.000)$ & $(0.000)$ & $(0.000)$ \\
& & & & \\
State FE & YES & YES & YES & YES \\
Birth Year FE & YES & YES & YES & YES \\
Time FE & YES & YES & YES & YES \\
State×Trend & YES & YES & YES & YES \\
& & & & \\
Observations & $1,238,781$ & $1,238,781$ & $1,238,781$ & $1,238,781$ \\
Pseudo R-squared & 0.0990 & 0.0971 & 0.0963 & 0.0942 \\
\hline
\end{tabular}

Table 10. Ordered Logit and Ordered Probit. Notes. This table presents ordered logit (columns 1-2) and ordered probit (columns 3-4) estimates for $\beta_{1}$ and $\beta_{2}$ from equation (5). The analogous specification in columns 4 and 8 of Table 3, were estimated using OLS. ${ }^{*} p<0.10,{ }^{* *} p<0.05,{ }^{* * *} p<0.01$. Standard errors in parentheses are clustered by state and year of birth.

which implemented midday meals earlier than the rest of the state. Column 2 excludes the earliest implementers - those states that instituted midday meals in 2002. Column 3 excludes the laggardsstates that implemented midday meals in 2005 or 2006. Finally, column 4 includes states and union territories that already had midday meals in place prior to the Supreme Court Mandate: Kerala, Gujarat, Pondicherry and Tamil Nadu.

The table shows, once more, that our findings are incredibly robust: the point estimates are almost identical to those in our main results in columns 4 and 8 of Table 3. They are not driven by pilot districts (column 1), early movers (column 2), or by laggards (column 3). The inclusion of preprogram implementers (column 4) also does nothing to alter the main result. Finally, dropping states one-by-one does not affect the results either, indicating that our findings do not hinge on any one state (results not shown.)

\section{CONCLUSION}

This paper has explored the effect of school feeding programs on children's learning achievement. What sets it apart from previous papers is that it studies a large-scale program using a large data set, and examines the effect of long-term program exposure. The results indicate that exposure to midday meals for the five-year duration of primary school increases test scores by 0.17 standard deviations ( $18 \%$ relative to children with the less than a year of exposure) for reading and 0.09 standard deviations $(9 \%)$ for math. 


\begin{tabular}{|c|c|c|c|c|}
\hline \multirow[b]{2}{*}{$\begin{array}{l}\text { Years of } \\
\text { Potential } \\
\text { Exposure }\end{array}$} & \multicolumn{4}{|c|}{ Sample } \\
\hline & $\begin{array}{l}\text { Excluding } \\
\text { pilot } \\
\text { districts }^{a} \\
\text { (1) }\end{array}$ & $\begin{array}{c}\text { Excluding } \\
\text { earliest } \\
\text { implementers }^{b} \\
\text { (2) }\end{array}$ & $\begin{array}{c}\text { Excluding } \\
\text { latest } \\
\text { implementers } \\
\text { (3) }\end{array}$ & $\begin{array}{c}\text { Including } \\
\text { pre-mandate } \\
\text { implementers } \\
\text { (4) }\end{array}$ \\
\hline & \multicolumn{4}{|c|}{ Reading } \\
\hline Exposure $\left(\beta_{1}\right)$ & $\begin{array}{c}0.017 * * * \\
(0.002)\end{array}$ & $\begin{array}{c}0.019 * * * \\
(0.003)\end{array}$ & $\begin{array}{c}0.021 * * * \\
(0.003)\end{array}$ & $\begin{array}{c}0.020 * * * \\
(0.002)\end{array}$ \\
\hline Exposure $^{2}\left(\beta_{2}\right)$ & $\begin{array}{c}-0.000 * * * \\
(0.000)\end{array}$ & $\begin{array}{c}-0.000 * * * \\
(0.000)\end{array}$ & $\begin{array}{c}-0.000 * * * \\
(0.000)\end{array}$ & $\begin{array}{c}-0.000 * * * \\
(0.000)\end{array}$ \\
\hline \multirow[t]{2}{*}{ Adjusted R-squared } & $\begin{array}{c}1,064,171 \\
0.280\end{array}$ & $\begin{array}{c}1,102,704 \\
0.276\end{array}$ & $\begin{array}{c}933,275 \\
0.299\end{array}$ & $\begin{array}{c}1,399,003 \\
0.278\end{array}$ \\
\hline & \multicolumn{4}{|c|}{ Math } \\
\hline $\begin{array}{l}\text { Months of } \\
\text { Exposure }(\beta) \\
\text { Months }^{2}\end{array}$ & $\begin{array}{c}0.013 * * * \\
(0.002) \\
-0.000 * * * \\
(0.000)\end{array}$ & $\begin{array}{c}0.012 * * * \\
(0.003) \\
-0.000^{* * *} \\
(0.000)\end{array}$ & $\begin{array}{c}0.016 * * * \\
(0.003) \\
-0.000 * * * \\
(0.000)\end{array}$ & $\begin{array}{c}0.015^{* * *} \\
(0.002) \\
-0.000^{* * *} \\
(0.000)\end{array}$ \\
\hline $\begin{array}{l}\text { Observations } \\
\text { Adjusted R-squared }\end{array}$ & $\begin{array}{c}1,064,171 \\
0.274\end{array}$ & $\begin{array}{c}1,102,704 \\
0.268\end{array}$ & $\begin{array}{c}933,275 \\
0.289\end{array}$ & $\begin{array}{c}1,399,003 \\
0.266\end{array}$ \\
\hline
\end{tabular}

Table 11. Different State Samples by Timing of Implementation Notes. This table presents estimates for $\beta_{1}$ and $\beta_{2}$ from equation (5) for different state samples. $a$. Excludes pilot districts, which implemented midday meals earlier than the rest of the state. $b$. Excludes states which implemented midday meals in 2002. c. Excludes states which implemented midday meals in 2005 or 2006. d. Includes pre-2001 implementers Kerala, Gujarat, Pondicherry and Tamil Nadu. ${ }^{*} p<0.10,{ }^{* *} p<0.05,{ }^{* * *} p<0.01$. Standard errors in parentheses are clustered by state and year of birth.

We further show that relatively disadvantaged children show no differential treatment response, probably because the children in this rural Indian sample are likely to have low baseline nutrition to begin with. There are complementarities between teaching- and learning-related classroom inputs, though not with more general schooling infrastructure. And there is limited evidence of intra-household redistribution, suggesting that this in-kind transfer "sticks" to its intended beneficiaries.

India's midday meal scheme is thought to be one of the least expensive in the world. By our estimates, discussed earlier, the cost of midday meal provision is US\$ 10 per child per year; Kristjansson et al. (2016) independently comes to the same estimate. This means that the cost of providing midday meals for the full 5 years of primary school amounts to US\$50 per child. 
To put the learning effects of this program in perspective midday meals would, by our calculations, be placed roughly on par with remedial education in India in terms of cost-benefit considerations (see Banerjee et al. (2007)). ${ }^{16}$ This is impressive compared to other schooling inputs: a recent review found that of 26 studies of schooling interventions, remedial education was by far the most effective. ${ }^{17}$ Of course, these costs are likely to be higher in areas which do not enjoy as well-developed a public primary school infrastructure and public food distribution system as India does. But then again, we have said nothing of the potential nutritional and health improvements arising from this intervention, which would only add to the benefits. All in all, this program seems like an excellent investment.

\footnotetext{
${ }^{16}$ The remedial tutoring program they evaluate cost about US\$33 per child and resulted in a 0.14 standard deviation increase in test scores after a year.

${ }^{17}$ See https://www.povertyactionlab.org/policy-lessons/education/increasing-test-score-performance, in particular the graph entitled "Improving Student Learning: Cost Effectiveness of Education Programs".
} 


\section{REFERENCES}

Adelman, S., H. Alderman, D. O. Gilligan, and K. Lehrer (2008). The impact of alternative food for education programs on learning achievement and cognitive development in Northern Uganda. Unpublished manuscript.

Afridi, F. (2010). Child welfare programs and child nutrition: evidence from a mandated school meal program in India. Journal of Development Economics 92(2), 152-165.

Afridi, F. (2011). The impact of school meals on school participation: evidence from rural India. Journal of Development Studies 47(11), 1636-1656.

Afridi, F., B. Barooah, and R. Somanathan (2014). School meals and classroom attention: evidence from India. Mimeo.

Ahmed, A. (2004). Impact of feeding children in school: evidence from Bangladesh. International Food Policy Research Institute.

Alderman, H. and D. Bundy (2012). School feeding programs and development: Are we framing the question correctly? The World Bank Research Observer 27(2), 204-221.

Angrist, J. D. and V. Lavy (1997). The effect of a change in language of instruction on the returns to schooling in Morocco. Journal of Labor Economics 15(1), S48-76.

ASER (2005). Annual Status of Education Report. Technical report, ASER.

Banerjee, A. V., S. Cole, E. Duflo, L. Linden, et al. (2007). Remedying education: Evidence from two randomized experiments in India. The Quarterly Journal of Economics 122(3), 1235-1264.

Behrman, J. R., S. W. Parker, and P. E. Todd (2010). Incentives for students and parents. Mimeo.

Belot, M. and J. James (2011). Healthy school meals and educational outcomes. Journal of Health Economics 30(3), 489-504.

Bhattacharya, J., J. Currie, and S. J. Haider (2006). Breakfast of champions? The school breakfast program and the nutrition of children and families. Journal of Human Resources 41(3), 445-466.

Bundy, D., C. Burbano, M. Grosh, A. Gelli, M. Jukes, and L. Drake (2009). Rethinking school feeding. Social safety nets, child development and the education sector. Directions in development. Human development, World Bank.

Das, J., S. Dercon, J. Habyarimana, P. Krishnan, K. Muralidharan, and V. Sundararaman (2013). School inputs, household substitution, and test scores. American Economic Journal: Applied Economics 5(2), 29-57.

Deaton, A. and Drèze (2009). Food and nutrition in India: Facts and interpretations. Economic and Political Weekly February 14, 42-65.

Desai, A. H. and S. Muralidhar (2000). Public interest litigation: Potential and problems. International Environmental Law Research Centre.

Drèze, J. and A. Goyal (2003). The future of mid-day meals. Economic and Political Weekly November 1, 4673-4683.

Educational Consultants India (2014). National sample survey of estimation of out-of-school children in the age 6-13 in India. Technical report, Educational Consultants India.

Grantham-McGregor, S. M., S. Chang, and S. P. Walker (1998). Evaluation of school feeding programs: some Jamaican examples. The American Journal of Clinical Nutrition 67(4), 785S-789S.

Jacoby, E. R., S. Cueto, and E. Pollitt (1998). When science and politics listen to each other: good prospects from a new school breakfast program in Peru. The American journal of clinical nutrition 67(4), 795S-797S.

Jacoby, H. G. (2002). Is there an intrahousehold flypaper effect? Evidence from a school feeding programme. The Economic Journal 112(476), 196-221. 
Jayaraman, R. and D. Simroth (2015). The impact of school lunches on primary school enrollment: evidence from India's midday meal scheme. The Scandinavian Journal of Economics 17(4), 11761203.

Jomaa, L. H., E. McDonnell, and C. Probart (2011). School feeding programs in developing countries: Impacts on children's health and educational outcomes. Nutrition Reviews 69(2), 83-98.

Kazianga, H., D. De Walque, and H. Alderman (2012). Educational and child labour impacts of two food-for-education schemes: Evidence from a randomised trial in rural Burkina Faso. Journal of African Economies 21(5), 723-760.

Kingdon, G. G. (2002). The gender gap in educational attainment in India: how much can be explained? Journal of Development Studies 39(2), 25-53.

Kingdon, G. G. (2007). The progress of school education in India. Oxford Review of Economic Policy 23(2), 163-195.

Kremer, M. and C. Vermeersch (2004). School meals, educational achievement and school competition: Evidence from a randomized evaluation. World Bank Policy Research Working Paper no. 2523.

Kristjansson, E., A. Gelli, V. Welch, T. Greenhalgh, S. Liberato, D. Francis, and F. Espejo (2016). Costs, and cost-outcome of school feeding programmes and feeding programmes for young children. evidence and recommendations. International Journal of Educational Development 48, 79 83.

Kristjansson, E., V. Robinson, M. Petticrew, B. MacDonald, J. Krasevec, L. Janzen, T. Greenhalgh, G. Wells, J. MacGowan, A. Farmer, B. Shear, A. Mayhew, and P. Tugwell (2007). School feeding for improving the physical and psychosocial health of disadvantaged students. Copenhagen: Campbell Review, SFI Campbell.

Lawson, T. M. (2012). Impact of school feeding programs on educational, nutritional, and agricultural development goals: A systematic review of literature. Master's thesis.

McEwan, P. J. (2013). The impact of Chile's school feeding program on education outcomes. Economics of Education Review 32, 122-139.

McEwan, P. J. (2015). Improving learning in primary schools of developing countries a meta-analysis of randomized experiments. Review of Educational Research 85(3), 353-394.

MHRD, G. o. I. Documentation on meal provision of midday meal scheme. Technical report. http://mdm.nic.in.

MHRD, G. o. I. Documentation on meal provision of midday meal scheme. Technical report. http://mdm.nic.in.

Muralidharan, K. (2006). Public-private partnerships for quality education in India. Mimeo.

Neumann, C. G., N. O. Bwibo, S. P. Murphy, M. Sigman, S. Whaley, L. H. Allen, D. Guthrie, R. E. Weiss, and M. W. Demment (2003). Animal source foods improve dietary quality, micronutrient status, growth and cognitive function in kenyan school children: background, study design and baseline findings. The Journal of Nutrition 133(11), 3941S-3949S.

Neumann, C. G., S. P. Murphy, C. Gewa, M. Grillenberger, and N. O. Bwibo (2007). Meat supplementation improves growth, cognitive, and behavioral outcomes in Kenyan children. The Journal of Nutrition 137(4), 1119-1123.

Powell, C. A., S. P. Walker, S. M. Chang, and S. M. Grantham-McGregor (1998). Nutrition and education: a randomized trial of the effects of breakfast in rural primary school children. The American Journal of Clinical Nutrition 68(4), 873-879.

PROBE (1999). Public Report on Basic Education. New Delhi: Oxford University Press. 
Secretariat of the Right to Food Campaign (2005, November). Midday meals: A primer. Right to Food Campaign Materials.

Singh, A. (2008). Do school meals work? Treatment evaluation of the midday meal scheme in India. Young Lives Student Paper.

Singh, A., A. Park, and S. Dercon (2014). School meals as a safety net: an evaluation of the midday meal scheme in India. Economic Development and Cultural Change 62(2), 275-306.

Strauss, J. (1986). Does better nutrition raise farm productivity? The Journal of Political Economy 94(2), 297-320.

Strauss, J. and D. Thomas (1998). Health, nutrition, and economic development. Journal of Economic Literature 36(2), 766-817.

Van Stuijvenberg, M. E., J. D. Kvalsvig, M. Faber, M. Kruger, D. G. Kenoyer, and A. S. Benadé (1999). Effect of iron, iodine, and $\beta$-carotene-fortified biscuits on the micronutrient status of primary school children: a randomized controlled trial. The American journal of clinical nutrition 69(3), 497-503.

WFP (2013). State of school feeding worldwide. Technical report, World Food Program. World Food Program annual report.

Whaley, S. E., M. Sigman, C. Neumann, N. Bwibo, D. Guthrie, R. E. Weiss, S. Alber, and S. P. Murphy (2003). The impact of dietary intervention on the cognitive development of Kenyan school children. The Journal of Nutrition 133(11), 3965S-3971S. 


\section{APPENDIX A}

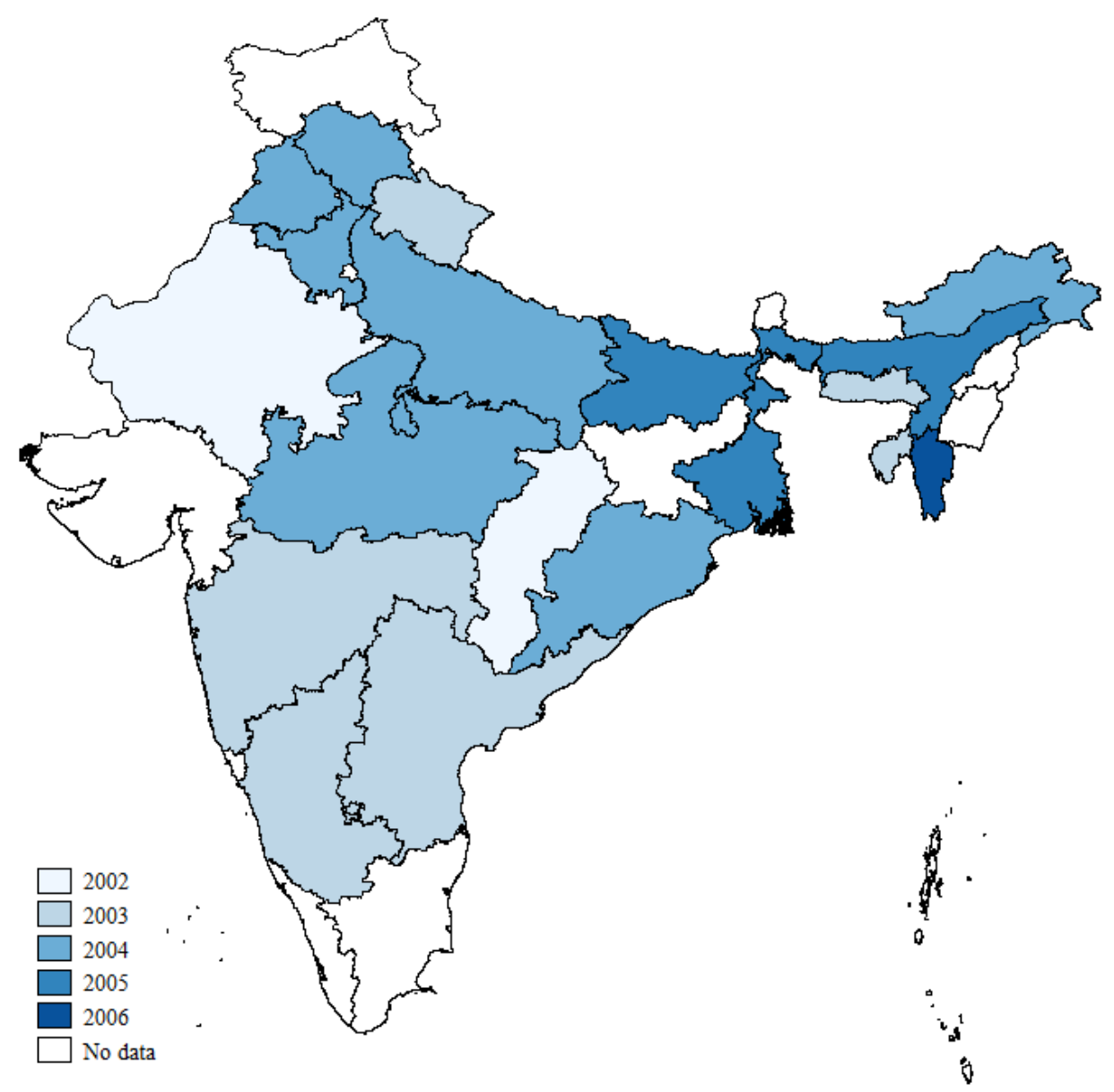

Figure A1. Timing of State-Level Implementation of Midday Meal Scheme. Notes. States marked in white are not included in the main sample. 
苞

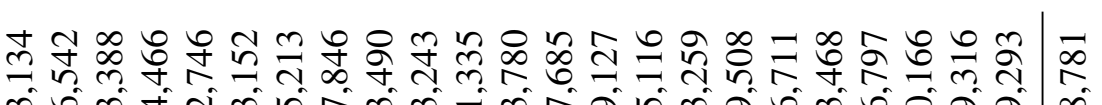
भं

귱

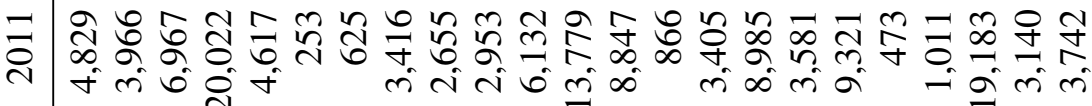

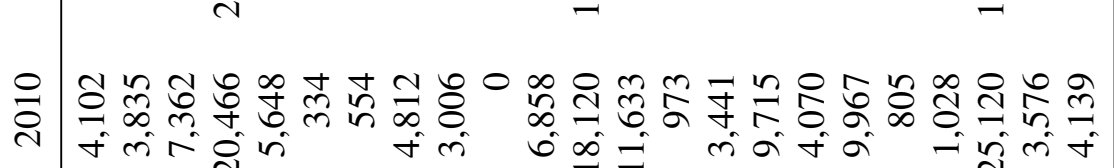

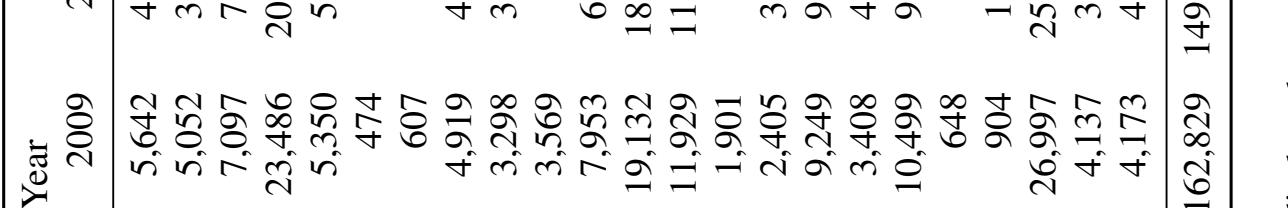

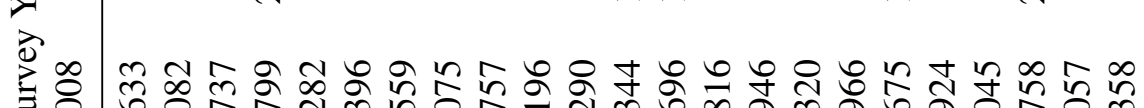

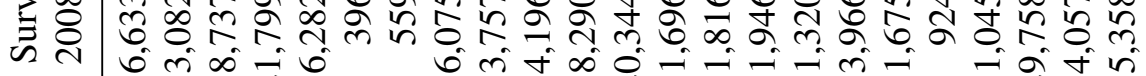

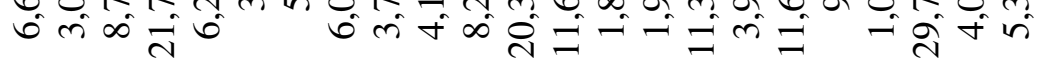

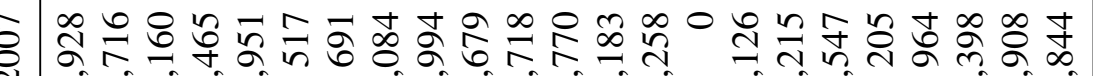

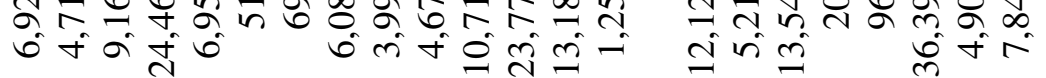

\&

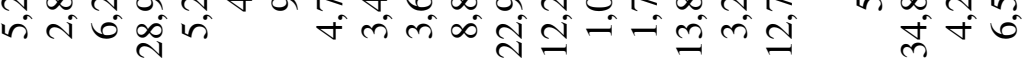

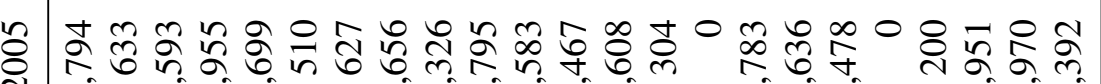

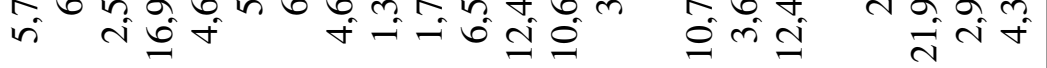

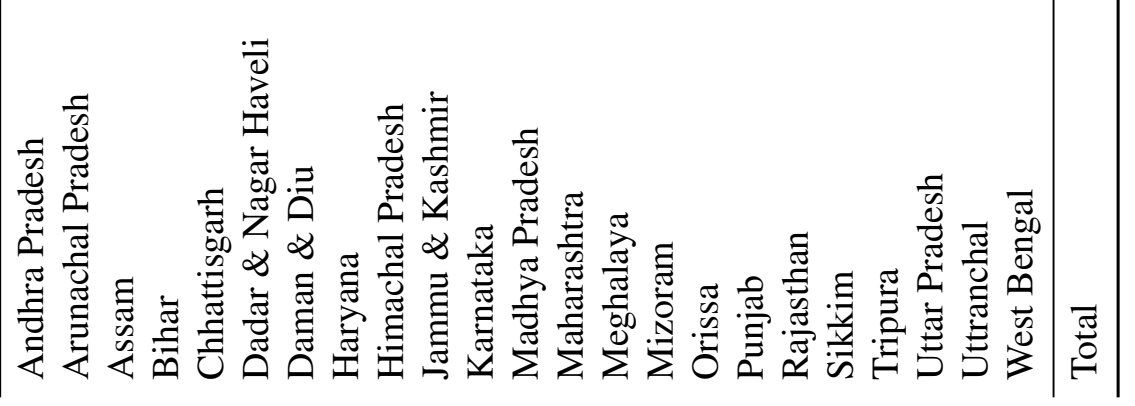




\begin{tabular}{lcccc}
\hline Sample: & \multicolumn{2}{c}{$2009-2012$} & \multicolumn{2}{c}{$2005-2012$} \\
\hline & Frequency & Percent & Frequency & Percent \\
\hline Age at Policy Start & $(1)$ & $(2)$ & $(3)$ & $(4)$ \\
\hline 0 & $1,46,793$ & 27.24 & $1,57,204$ & 12.69 \\
1 & 92,766 & 17.22 & $1,07,716$ & 8.7 \\
2 & $1,00,005$ & 18.56 & $1,39,404$ & 11.25 \\
3 & 88,797 & 16.48 & $1,60,377$ & 12.95 \\
4 & 63,558 & 11.8 & $1,71,218$ & 13.82 \\
5 & 34,961 & 6.49 & $1,62,106$ & 13.09 \\
6 & 11,392 & 2.11 & $1,37,719$ & 11.12 \\
7 & 565 & 0.1 & $1,02,655$ & 8.29 \\
8 & - & - & 64,285 & 5.19 \\
9 & - & - & 29,870 & 2.41 \\
10 & - & - & 6,227 & 0.5 \\
Total & $5,38,837$ & 100 & $12,38,781$ & 100 \\
\hline
\end{tabular}

Table A2. Age Distribution at Policy Start. Notes. This table depicts children's age distribution in the 2009-2012 sample and main 2005-2012 sample, respectively. It demonstrates the absence of older children in the 2009-2012 sample. 


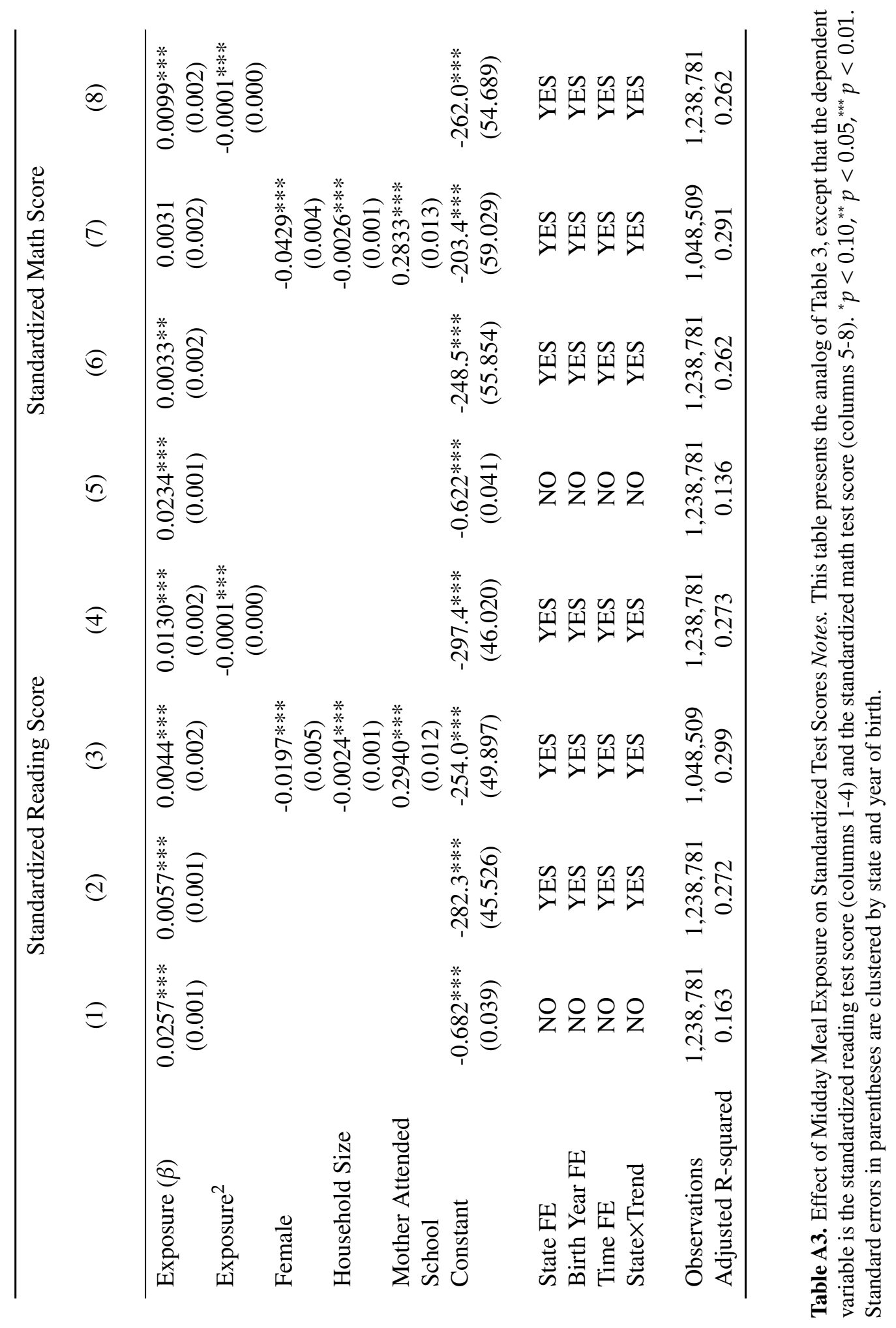




\begin{tabular}{|c|c|c|c|c|c|c|}
\hline \multirow{2}{*}{$\begin{array}{l}\text { Years of } \\
\text { Exposure }\end{array}$} & \multicolumn{3}{|c|}{ Reading Score } & \multicolumn{3}{|c|}{ Math Score } \\
\hline & (1) & (2) & (3) & (4) & (5) & (6) \\
\hline 1 to 2 & $\begin{array}{c}0.468 * * * \\
(0.049)\end{array}$ & $\begin{array}{c}0.057 * * \\
(0.025)\end{array}$ & $\begin{array}{c}0.118 * * * \\
(0.029)\end{array}$ & $\begin{array}{c}0.441 * * * \\
(0.046)\end{array}$ & $\begin{array}{c}0.025 \\
(0.026)\end{array}$ & $\begin{array}{c}0.092 * * * \\
(0.030)\end{array}$ \\
\hline 2 to 3 & $\begin{array}{c}0.935^{* * *} * \\
(0.059)\end{array}$ & $\begin{array}{c}0.200 * * * \\
(0.032)\end{array}$ & $\begin{array}{c}0.220 * * * \\
(0.047)\end{array}$ & $\begin{array}{c}0.822 * * * \\
(0.056)\end{array}$ & $\begin{array}{c}0.133 * * * \\
(0.035)\end{array}$ & $\begin{array}{c}0.170 * * * \\
(0.049)\end{array}$ \\
\hline 3 to 4 & $\begin{array}{c}1.320 * * * \\
(0.067)\end{array}$ & $\begin{array}{c}0.238 * * * \\
(0.042)\end{array}$ & $\begin{array}{c}0.275^{* * *} \\
(0.055)\end{array}$ & $\begin{array}{c}1.138^{* * *} * \\
(0.064)\end{array}$ & $\begin{array}{c}0.137 * * * \\
(0.046)\end{array}$ & $\begin{array}{c}0.187 * * * \\
(0.060)\end{array}$ \\
\hline 4 to 5 & $\begin{array}{c}1.549 * * * \\
(0.071)\end{array}$ & $\begin{array}{c}0.231 * * * \\
(0.061)\end{array}$ & $\begin{array}{c}0.281 * * * \\
(0.070)\end{array}$ & $\begin{array}{c}1.338^{* * * *} \\
(0.069)\end{array}$ & $\begin{array}{l}0.119^{*} \\
(0.070)\end{array}$ & $\begin{array}{c}0.186 * * \\
(0.081)\end{array}$ \\
\hline Female & & & $\begin{array}{c}-0.027 * * * \\
(0.007)\end{array}$ & & & $\begin{array}{c}-0.055^{* * * *} \\
(0.006)\end{array}$ \\
\hline Household Size & & & $\begin{array}{c}-0.002 * * * \\
(0.001)\end{array}$ & & & $\begin{array}{c}-0.002 * * * \\
(0.001)\end{array}$ \\
\hline Mother Attended & & & $0.399 * * *$ & & & $0.360 * * *$ \\
\hline School & & & $(0.016)$ & & & $(0.016)$ \\
\hline State FE & NO & YES & YES & NO & YES & YES \\
\hline Birth Year FE & NO & YES & YES & NO & YES & YES \\
\hline Time FE & NO & YES & YES & $\mathrm{NO}$ & YES & YES \\
\hline State $\times$ Trend & NO & YES & YES & NO & YES & YES \\
\hline $\begin{array}{l}\text { Mean at } \\
0 \text { to } 1 \text { Year }\end{array}$ & 1.301 & 1.301 & 1.098 & 1.262 & 1.262 & 1.084 \\
\hline Observations & $1,238,781$ & $1,238,781$ & $1,048,509$ & $1,238,781$ & $1,238,781$ & $1,048,509$ \\
\hline Adjusted R-squared & 0.155 & 0.274 & 0.303 & 0.130 & 0.265 & 0.298 \\
\hline
\end{tabular}

Table A4. Effect of Midday Meal Exposure on Test Scores, by Years of Potential Exposure Notes. This table provides OLS estimates for $\beta^{\prime}$ in equation (2). The exclusion is 0-12 months (i.e. less than 1 year) of potential exposure; 1-2 years correspond to 13-24 months, 2-3 correspond to 25-36 months, and so on. The mean test score for 1-12 months of potential exposure are presented in the third row from the bottom. ${ }^{*} p<0.10,{ }^{* *} p<0.05,{ }^{* * *} p<0.01$. Standard errors in parentheses are clustered by state and year of birth. 


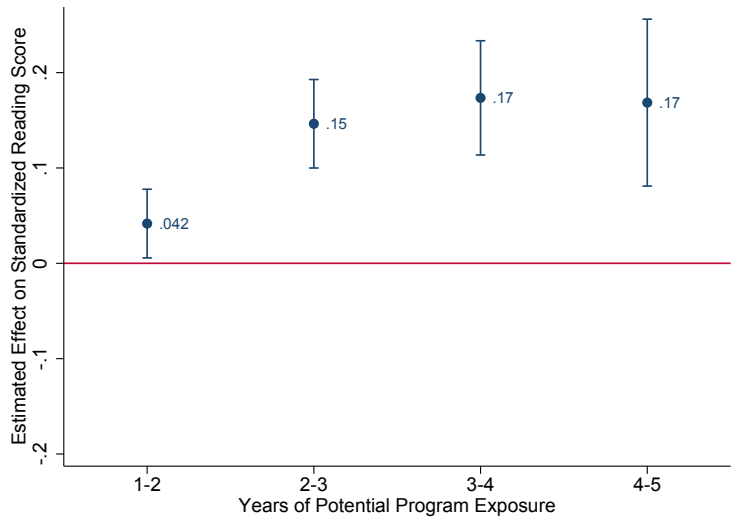

(a) Standardized Reading Score

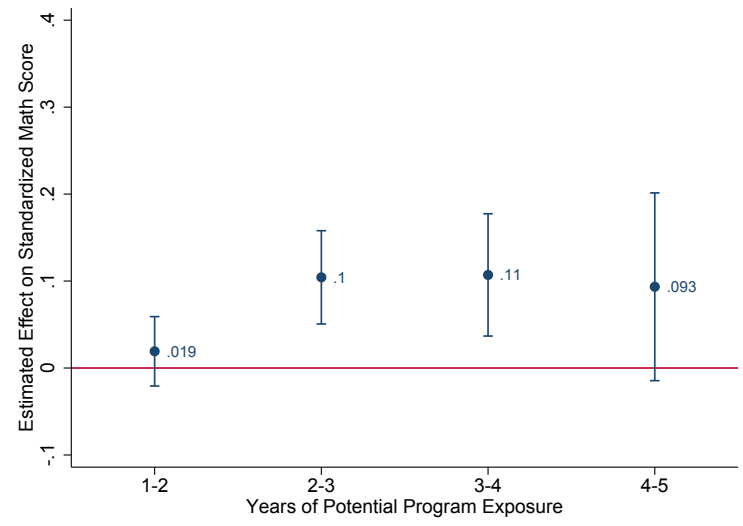

(b) Standardized Math Score

Figure A2. Effect of Midday Meal Exposure on Standardized Test Scores, by Year. Notes: This graph is analogous to Figure 6, except that the marginal effects pertain to standardized rather than raw test scores. Full regression estimates are presented in Table A4. The bars denote the corresponding 95\% confidence intervals, with standard errors clustered by state and year of birth.

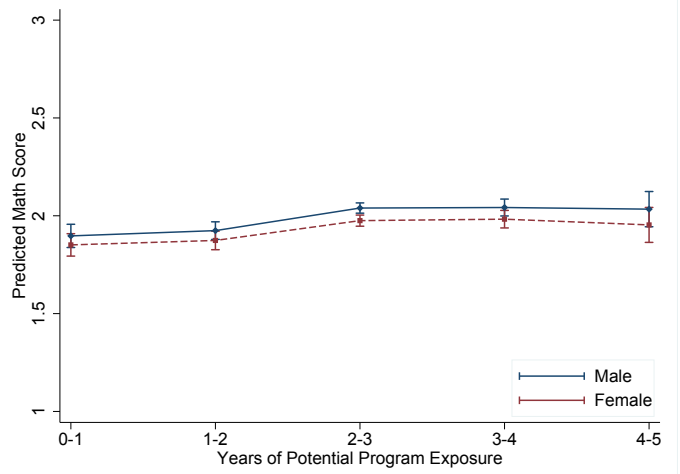

(a) Gender

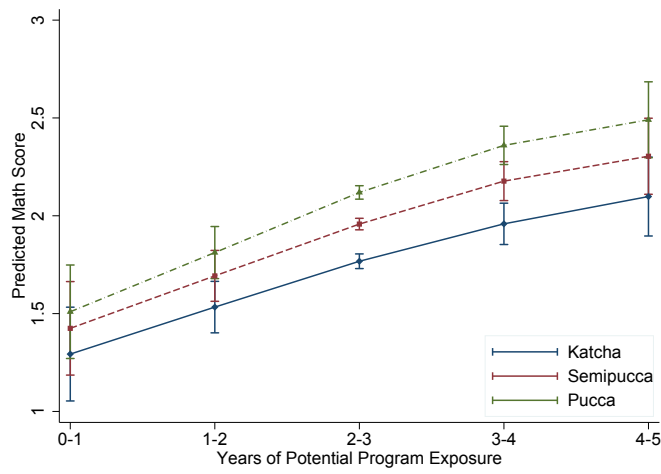

(b) Housing

Figure A3. Heterogeneous Responses. Notes: The graph above depicts predicted math test scores for different years of potential exposure by gender (panel a) and housing assets (panel b). Bars denote $95 \%$ confidence intervals, with standard errors clustered by state and time. 


\begin{tabular}{lccc}
\hline $\begin{array}{l}\text { Years of } \\
\text { Exposure }\end{array}$ & $\begin{array}{c}\text { Enrollment } \\
(1)\end{array}$ & $\begin{array}{c}\text { Dropout } \\
(2)\end{array}$ & $\begin{array}{c}\text { Never Enrolled } \\
(3)\end{array}$ \\
\hline 1 to 2 & 0.003 & -0.001 & -0.002 \\
& $(0.004)$ & $(0.001)$ & $(0.004)$ \\
to 3 & 0.003 & -0.001 & -0.001 \\
& $(0.004)$ & $(0.002)$ & $(0.004)$ \\
3 to 4 & 0.003 & -0.001 & -0.002 \\
& $(0.005)$ & $(0.002)$ & $(0.006)$ \\
4 to 5 & -0.006 & 0.003 & 0.004 \\
& $(0.007)$ & $(0.003)$ & $(0.007)$ \\
& & & \\
State FE & YES & YES & YES \\
Birth Year FE & YES & YES & YES \\
Time FE & YES & YES & YES \\
StateXTrend & YES & YES & YES \\
& & & \\
Mean at & 0.960 & 0.006 & 0.034 \\
0 to 1 Year & & & \\
Observations & $1,238,781$ & $1,238,781$ & $1,238,781$ \\
Adjusted R-squared & 0.024 & 0.005 & 0.026 \\
\hline
\end{tabular}

Table A5. Effect of Midday Meal Exposure on School Participation Notes. This table presents OLS estimates for $\beta^{\prime}$ in equation 2, with binary measures of school participation (rather than test scores) on left hand side of the equation: dummy variables equal to 1 if the child is currently enrolled in school (column 1), is a school dropout (column 2) or has never been enrolled in school. Note that the dependent variable in column 1 is simply 1 minus the sum of the dependent variables in columns 2 and 3 . The latter 2 columns therefore show where increased enrollment is come from: dropouts or never-enrolled children. The exclusion is 0-1 years of potential exposure. The proportion of enrolled, dropouts and never-enrolled for the baseline ( $0-1$ years of potential exposure) are presented in the third row from the bottom. ${ }^{*} p<0.10,{ }^{* *} p<0.05,{ }^{* * *} p<0.01$. Standard errors in parentheses are clustered by state and year of birth. 


\section{APPENDIX B}

This appendix details how the potential program exposure variable in months was constructed. Each cross section of the household survey contains a variable measuring the child's current age in years. From this, one can deduce the child's age in the year in which midday meals were introduced in their state. Children officially enroll in grade 1 in the year in which they turn 6. Primary school lasts for 5 years. Assuming annual grade promotion, the child will leave primary school in the year they turn 11. Given that the mandate only covered primary schools, a child can therefore have a maximum of 5 years, or 60 months of program exposure. Since tests are administered in October, however, this is only true of 11 year-olds; 10 year-olds, by contrast, can have a maximum of only 52 months of exposure. When calculating the number of months of exposure, however, three things need to be taken into account: (i) when the academic year, i.e. initial enrollment or grade promotion, begins, (ii) the month in which the program was introduced, and (iii) the month in which children were tested. In India, the academic year begins in June. ASER surveys are conducted sometime between September and November; the precise date varies from year-to-year and state-to-state, and the precise timing is not documented. We therefore chose the median month, October, as the test month.

The number of months a child has been exposed to the program by October of any given survey year therefore depends upon (a) their current age and (b) their age at the time of midday meal introduction. Table A6 describes the construction of the (months of potential) Exposure variable in detail. 


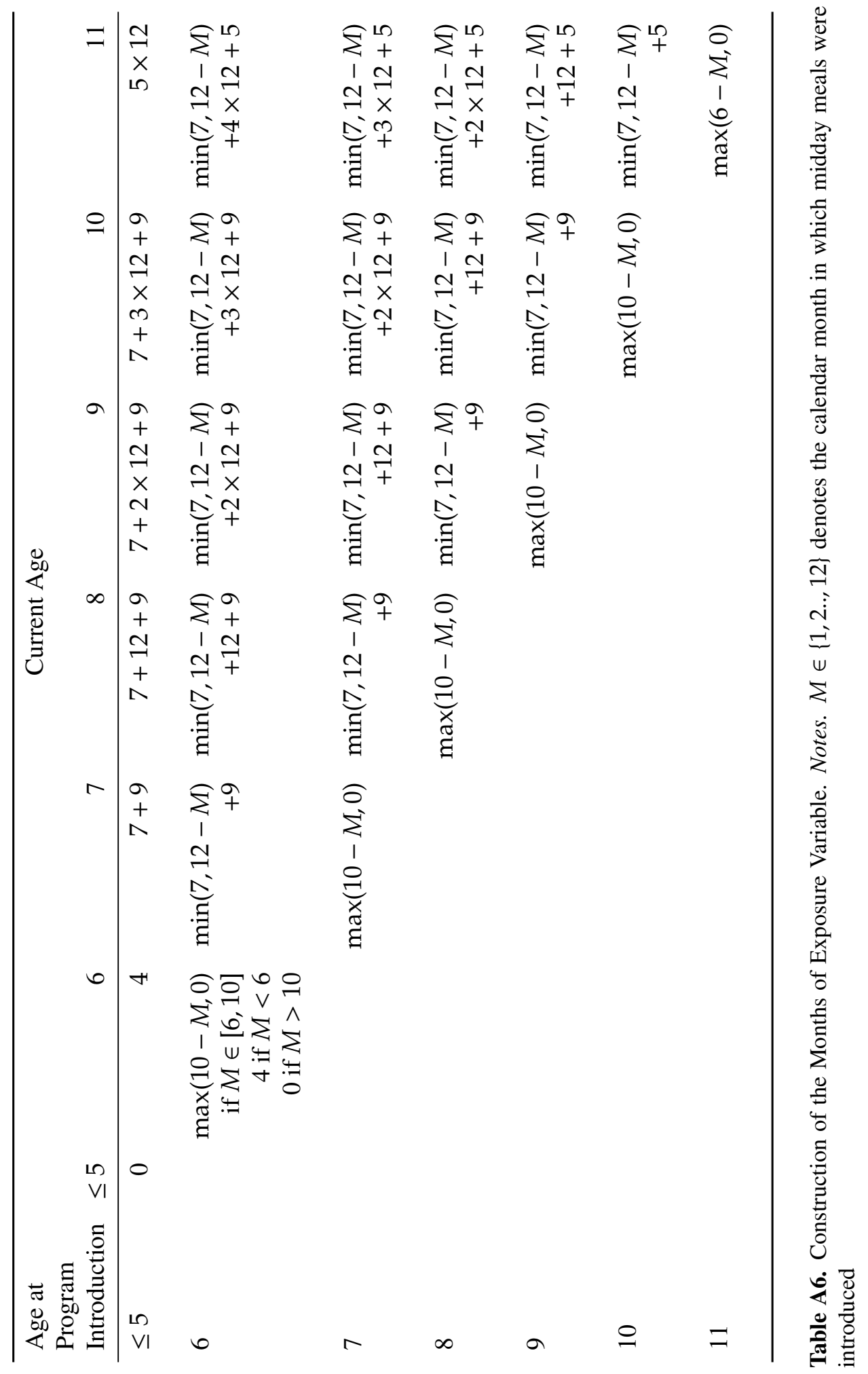

